\title{
ALGORITHMS FOR GEOMETRICAL MODELS IN BORROMINI'S SAN CARLINO ALLE QUATTRO FONTANE
}

\author{
Corrado Falcolini \\ Roma Tre University, Italy
}

\begin{abstract}
Construction of mathematical models of the vault of Borromini's San Carlino alle Quattro Fontane based on parametric curves and surfaces, including the shape of the vault and rules for its tessellation with crosses and octagonal coffers. Several models of different complexity are optimized and tested measuring their distance from the point cloud of a very accurate 3D survey and the analysis of such measured data is proposed to validate hypothesis of construction procedures by checking symmetries of coffers shape, scale and position in different levels and sectors. Some original algorithms are discussed to produce regular tessellations on a surface with a generic base curve and to construct regular parametric curves section out of simple point cloud data.
\end{abstract}

\section{KEY WORDS}

Parametric curves, parametric surfaces, tessellations, mathematical models, distance measure, Borromini, symmetry, point clouds, optimization, algorithms.

\section{INTRODUCTION}

Borromini's architectures, despite their appearance, are usually based on elementary geometry at the beginning of the design process, that become progressively more complex during the evolution of the construction defining spaces and shapes. In the case of San Carlo alle Quattro Fontane (San Carlino because of its small size, 1642) the vault surface and its base curve have been extensively studied, with several surveys (see Portoghesi 1967, Sartor 2000, AA.VV. 2007) and sometimes different conclusions. Moreover, the particularly innovative shape of the vault and its decoration has prevented the construction of simple mathematical models which could capture both the elegance and the structural aspects of such masterpiece of Roman baroque architecture.

Starting from a new survey (see Canciani et al., 2013) several models are presented and tested measuring their closeness to the point cloud of the survey or to a set of reference points.

The main goal of the present study is to derive simple geometrical models close to the shapes and structure detected in San Carlino that could help in the analysis of the construction procedures and in the definition of its final symmetries and appearance.

The model itself, as a list of parametric curves and surfaces, could also be used as a starting point for new projects.

Algorithms for the definition of the parametric models are given in an explicit form, in particular regarding the actual shape of the base curve and the geometrical shape of the vault and of its decorations. The results are supported by images and pictures and are tested using some distance function from the point clouds of the survey. 


\section{SECTION CURVES}

Starting from a cloud data of 4 million points, we select those points which are sufficiently close to a given plane and we project them on that plane: in this way we get horizontal and vertical sections of the point cloud.

In order to get a curve section we wrote an algorithm to get a parametric planar regular curve which fits the selected points (see Canciani et al., 2013) and automatically makes the selection on the curve of some nodal points with given specific characteristics (symmetry, tangency conditions, corners, .... ).
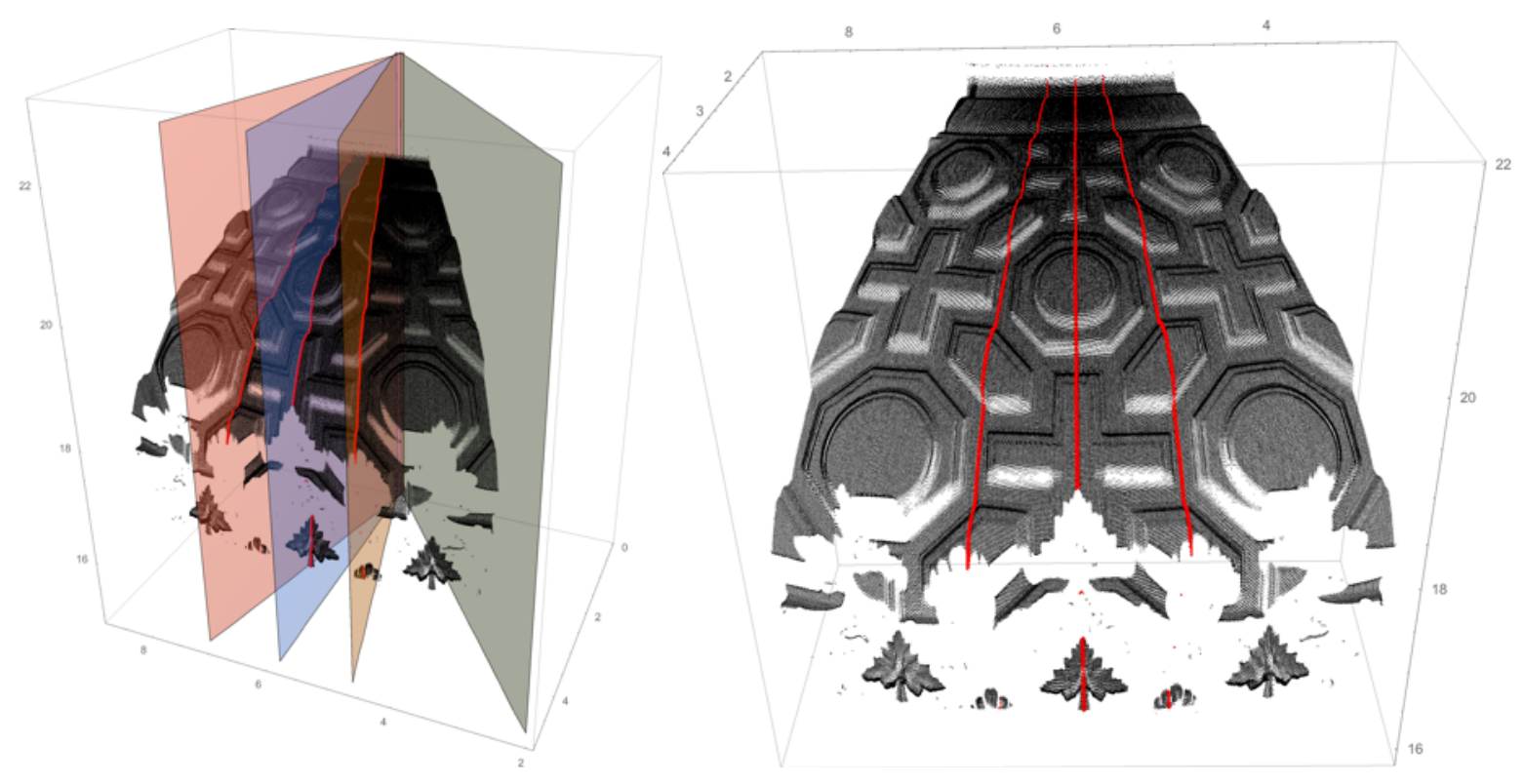

Figure 1. Parametric curves fitting the point cloud selection for given vertical planes.
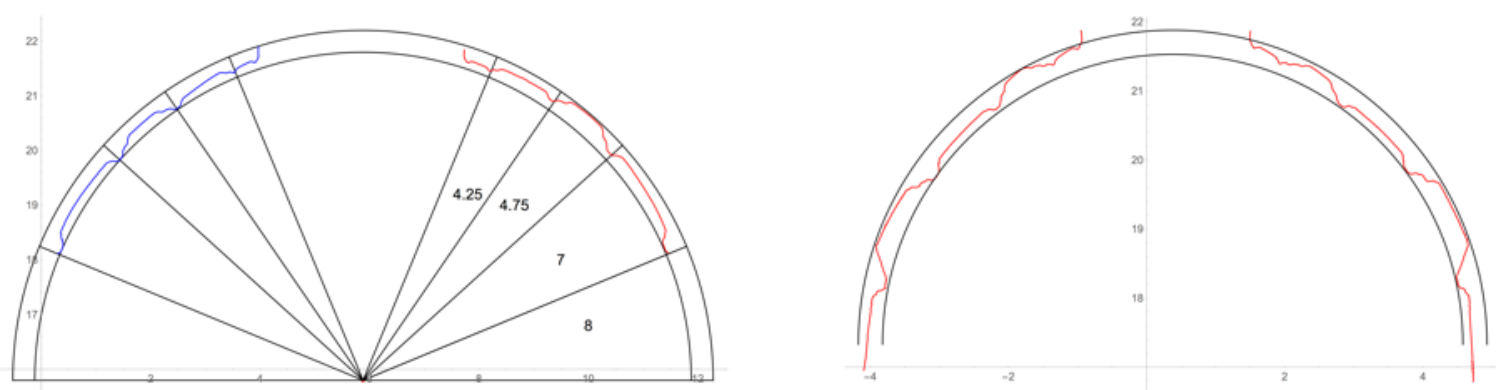

Figure 2. Parametric curves fitting the point cloud selection. Comparison with circular arcs. 


\section{GEOMETRY. The geometric reason for design}

Volume 1

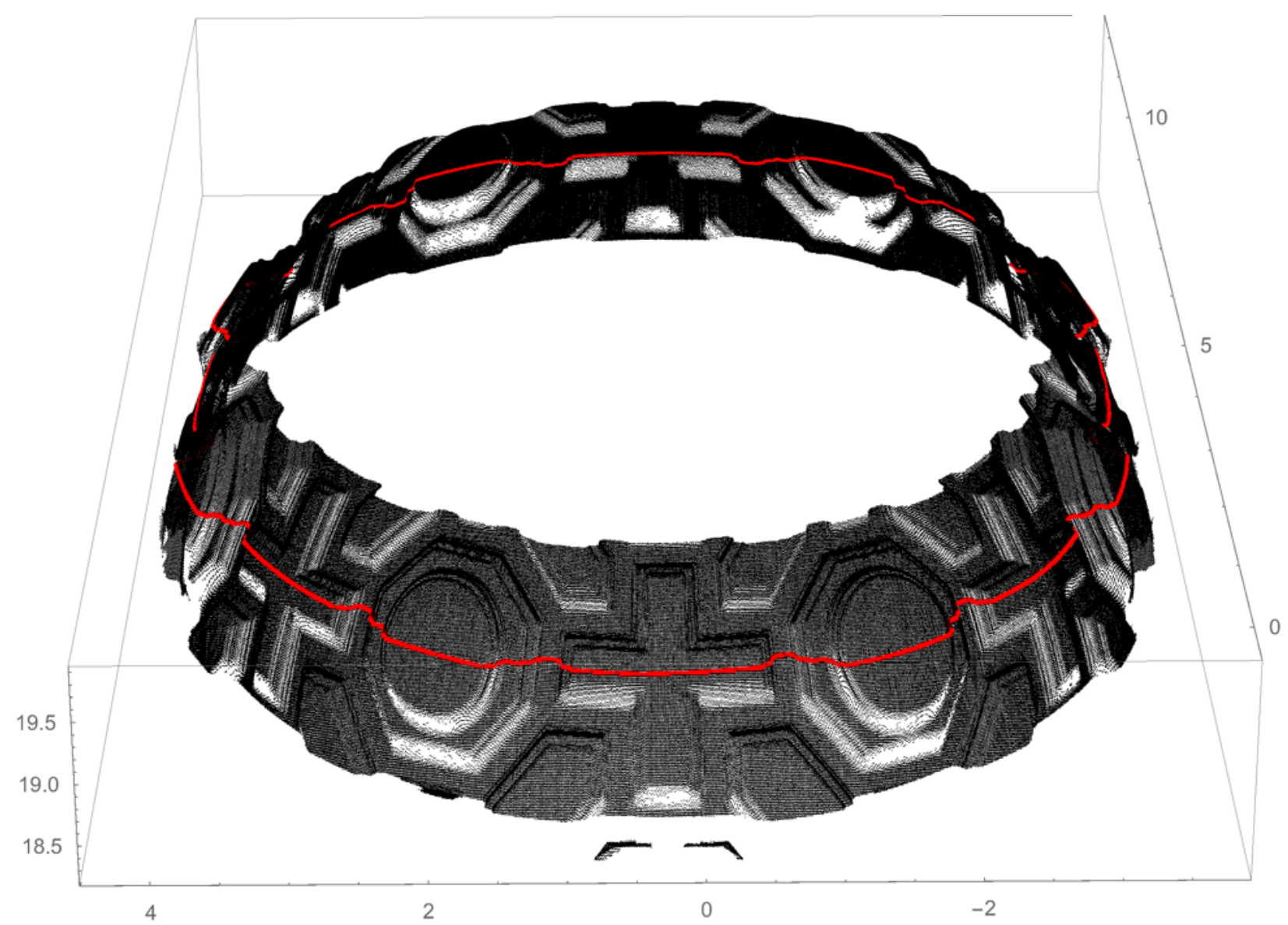

Figure 3. Selection of points (in red) close to the horizontal plane $z=z_{0}=19.2$, passing through the lacunars centers of the third level.

Some oval and the chosen epitrochoid are almost undistinguished (see Figure 3). Note that the point cloud selection, projected back onto the plane of section, is not symmetrical. 
GEOMETRY. The geometric reason for design

Volume 1

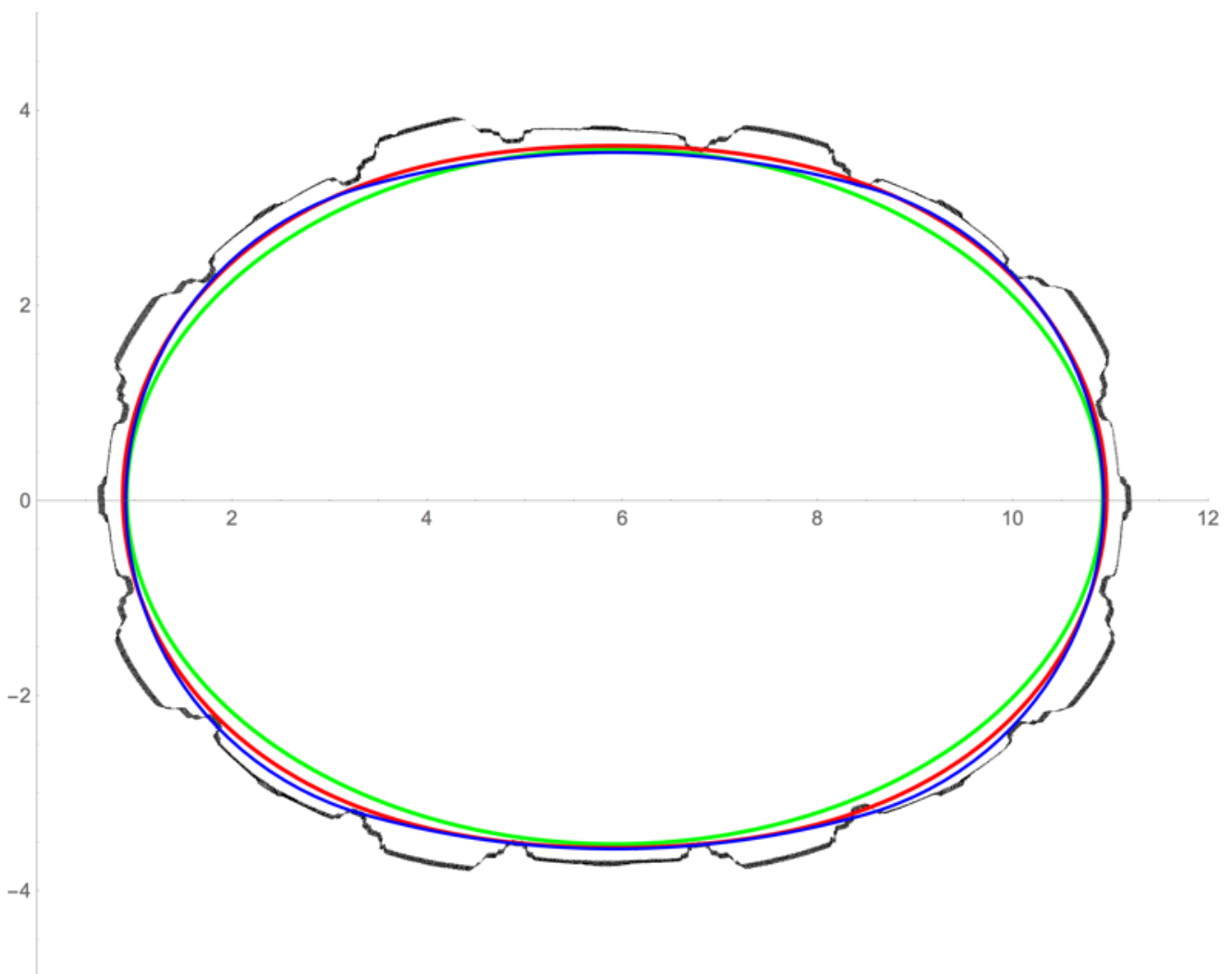

Figure 3. Section with the horizontal plane $z=z_{0}=19.2$. Comparison between an ellipse (green), an oval (red) and an epitrochoid (blue). The red and the blue curves are almost overlapping. 


\section{GEOMETRY. The geometric reason for design}

Volume 1
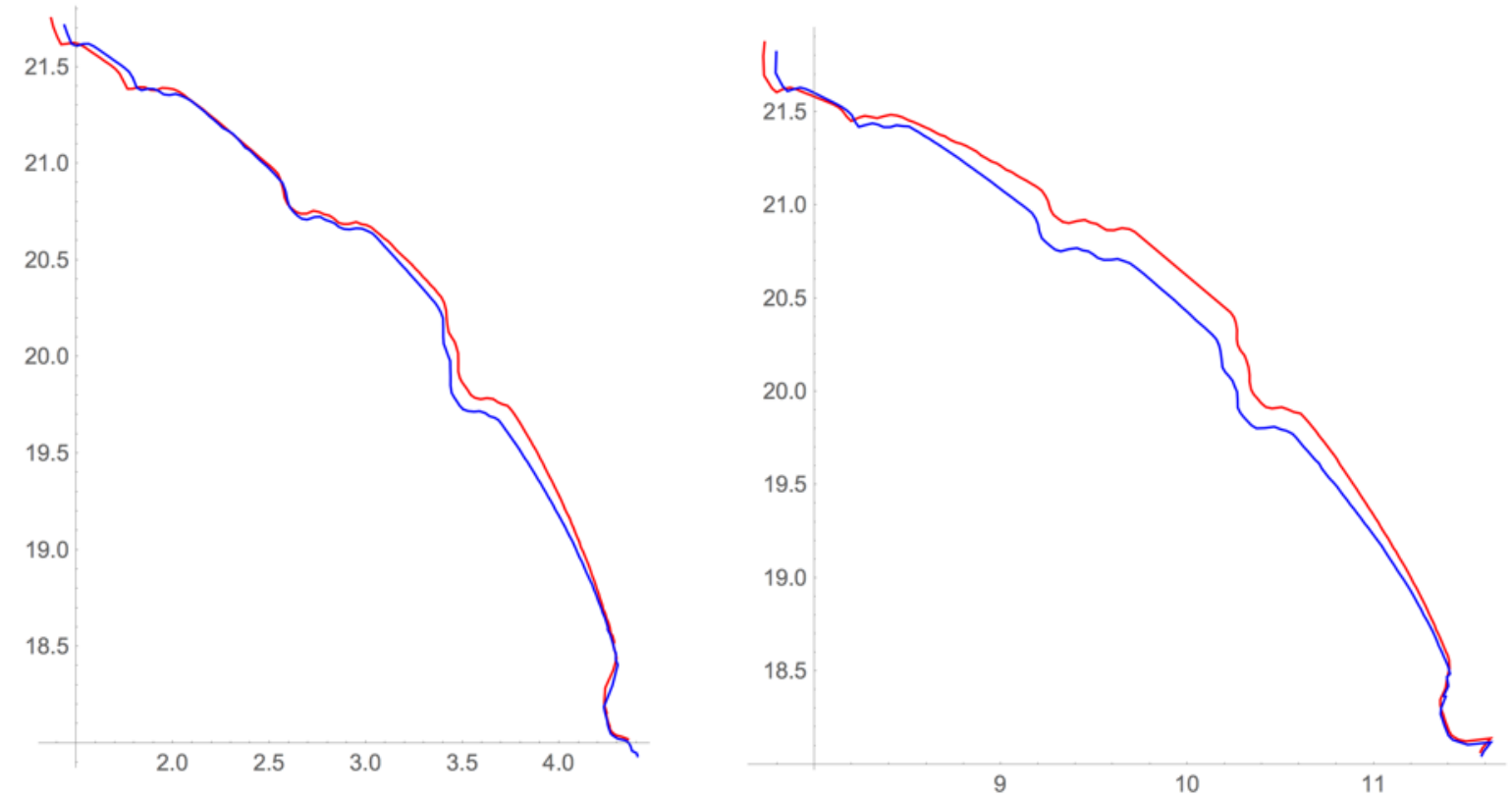

Figure 3. Parametric curves fitting the point cloud selection. Comparison on symmetrical sections of $(y, z)$-plane (left) and $(x, z)$-plane (right). The differences are greater on the $(x, z)$-plane.

\section{Ovals}

Different kind of ovals have been used in Borromini's project and using planar sections of the point cloud is possible to investigate their relations with the construction. Here we will show only some example: sometimes is difficult to choose which kind of oval would best fit the data so we propose to check ovals of a given type with some additional constraint.

In particular let us consider a particular variant of the Serlio's oval of the fourth kind, based on two circles both passing through the center of the other one, by fixing the angular position $\theta$ of the contact point (where the circles have the same tangent) to be $\theta=1.29815 \ldots$ (with successive best approximants $2 / 5 \pi, 5 / 12 \pi, 7 / 17 \pi, 12 / 29 \pi$ ) which gives the length ratio of the two circular arcs equal to $3 / 5$ (see Figure 4 ).

In fact, let $\mathrm{r}$ be the radius of the circle centered at $\mathrm{C}_{1}=(\mathrm{x}, 0)$ and $\mathrm{r}_{2}$ be the radius of the circle centered at $\mathrm{C}_{2}$, the construction implies $r=2 x$ and $r_{2}=r+x / \cos \theta$ and the condition to be imposed is

which gives

$$
\frac{r \cdot 2 \theta}{5}=\frac{r_{2}(\pi-2 \theta)}{3}
$$

and finally the equation

$$
\frac{r \cdot 2 \theta}{5}=\left(r+\frac{x}{\cos \theta}\right) \frac{(\pi-2 \theta)}{3}
$$

$$
\cos \theta=-\frac{5(\pi-2 \theta)}{2(5 \pi-16 \theta)}
$$




\section{GEOMETRY. The geometric reason for design}

Volume 1

solved by the approximate value $\theta=1.29815$.

Such a particular value allows to draw 5 lacunars on one circle and 3 lacunars on the other one keeping their horizontal size uniform.
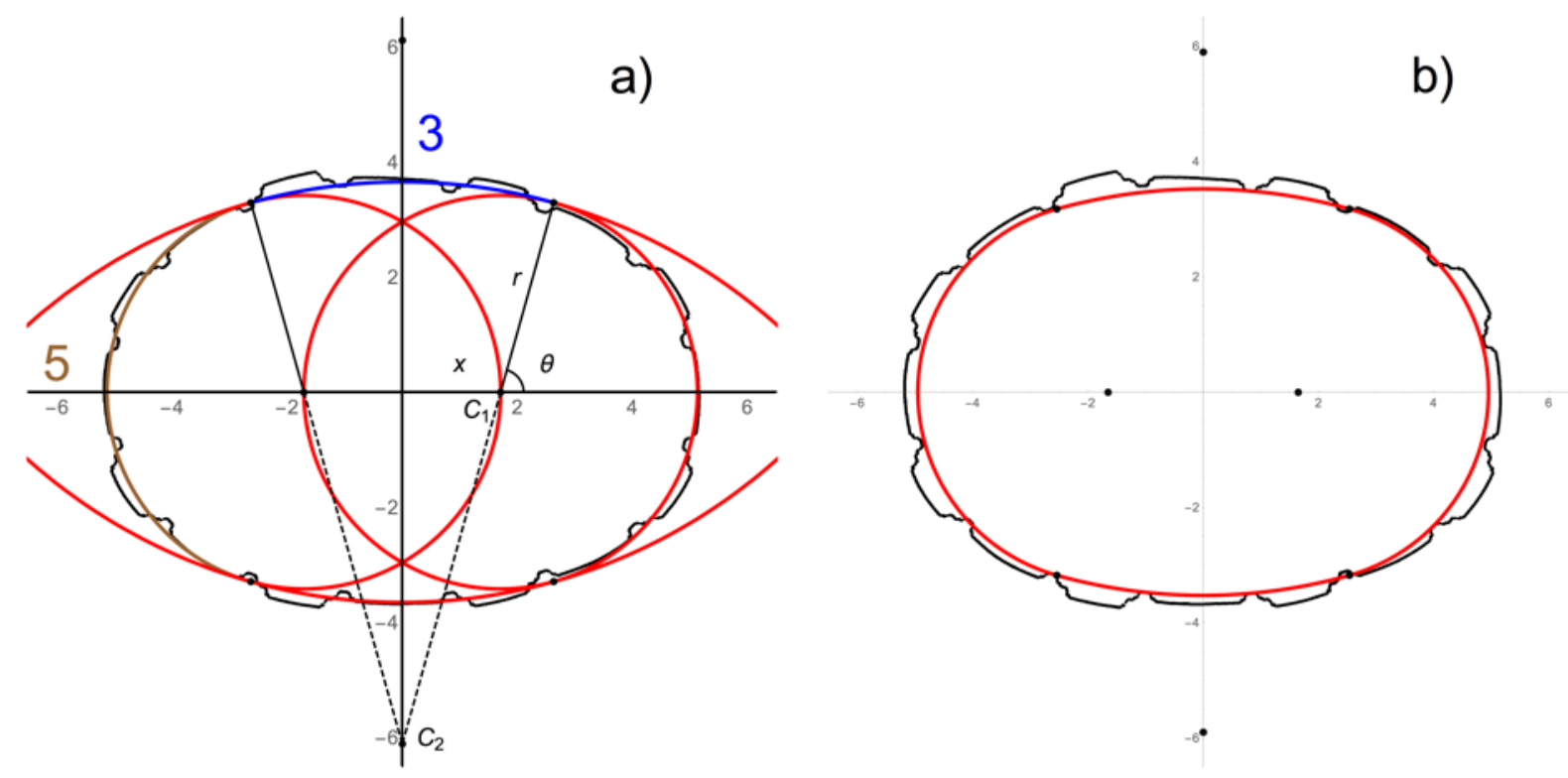

Figure 4. Oval construction on a horizontal section of the point cloud through the lacunars centers of the third level. a) $\theta=1.29815 \ldots$ implies the arc ratio of 3/5. b) Same oval passing on the intradox.

\section{The base curve}

The base curve is found indirectly as a curve at a constant distance from the frame decoration curve: using the software Mathematica (see Figure 9) it is possible to test dynamically the curves of a given shape manipulating the corresponding parameters. 


\section{GEOMETRY. The geometric reason for design}

Volume 1

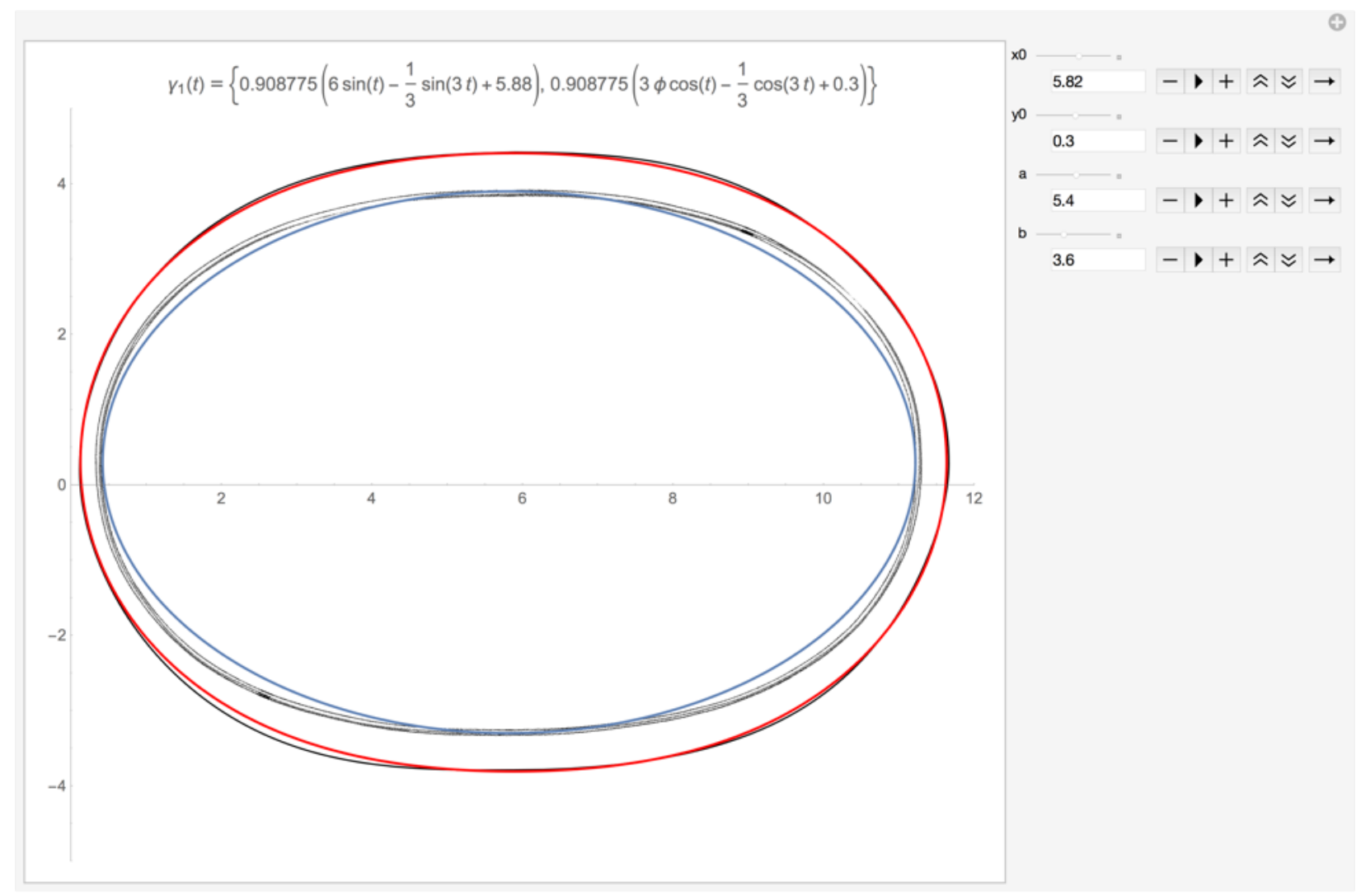

Figure 9. The base curve is found indirectly as a curve at a constant distance from the frame decoration curve. 


\section{GEOMETRY. The geometric reason for design}

Volume 1

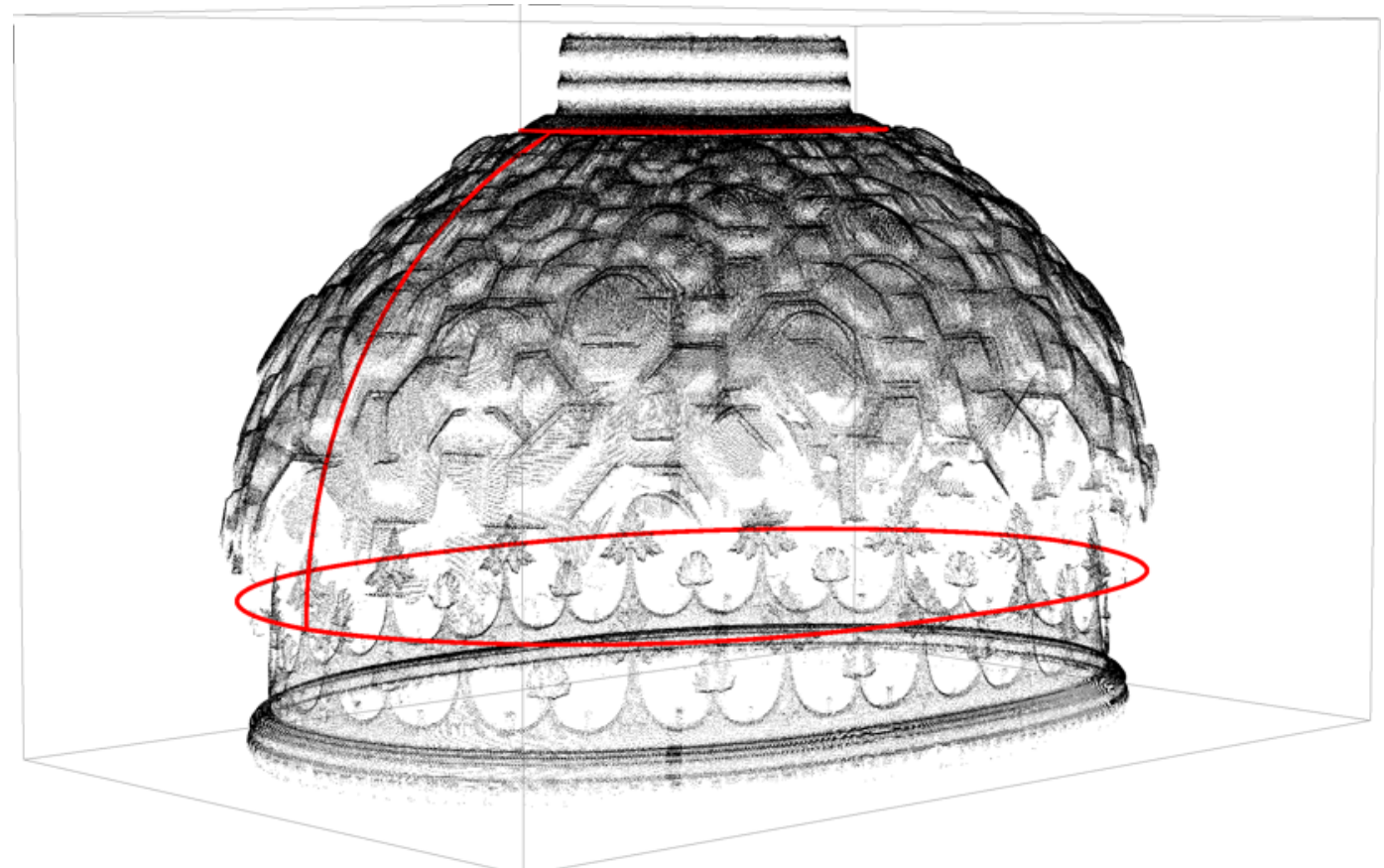

Figure 5. The base curve is found indirectly as a curve at a constant distance from the frame decoration curve. In this picture the vertical curve is a circular arc.

Often the curve at the base of the vault is related, to some extent, to an ellipse or, respecting the original Borromini's design, to an oval.

For instance S. Huerta, in a paper about oval domes (Huerta, 2007), wrote of San Carlino: "the oval which generates the plan changes at the base of the dome. This last oval deviates very much from the usual form of ovals so far. No doubt, Borromini chose this form to provide tension in the space. Neither of the ovals corresponds with Serlio's models" (see Serlio 1566, where Serlio, 14751554, defines four kind of ovals).

Ovals and ellipses could be very similar in shape but are very different mathematically: both are smooth curves but the oval, being the union of circular arcs, has the second derivative (and then the curvature) which is only piecewise constant. This discontinuity in the curvature makes the oval structurally more fragile than the ellipse which then seems a good trial precisely in the direction of taking into account the physical tension of the structure. But there is a third way: in fact in (Falcolini\&Vallicelli, 2011) a curve was proposed which had some feature of an oval but the regularity of an ellipse and seems to fit well some of the horizontal sections even if they corresponds to different kind of ovals.

\section{The epitrochoid}




\section{GEOMETRY. The geometric reason for design}

Volume 1

The epitrochoid, like the ellipse, is a particular epicycloid: it represents the trajectory of a given point at distance $\mathrm{h}$ from the center of a circle of radius $r$ which rolls around a fixed circle of radius $R$, so in particular it would be simple to device a graphical machine to draw it. The equation of the epitrochoid is:

$$
\begin{aligned}
& x=(R+r) \cos t-h \cos \frac{R+r}{r} t \\
& y=(R+r) \sin t-h \sin \frac{R+r}{r} t
\end{aligned}
$$

In the particular case of $h=1 / 3$ (Fig. 1c) two features are reached: regions with almost constant curvature (circular arcs) and points with zero curvature (linear neighborhood).

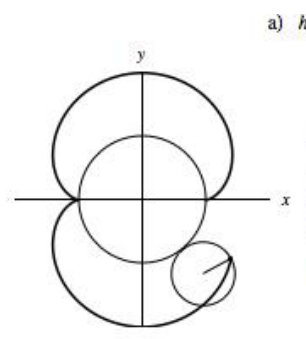

a) $h=1$

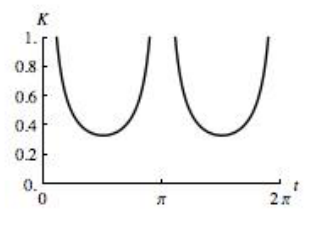

c) $h=\frac{1}{3}$

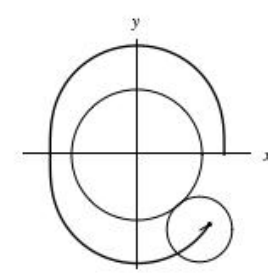

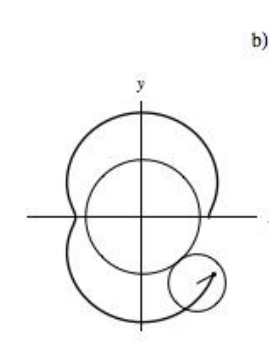

b) $h=\frac{2}{3}$

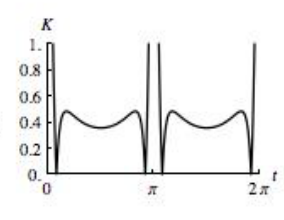

d) $h=0$
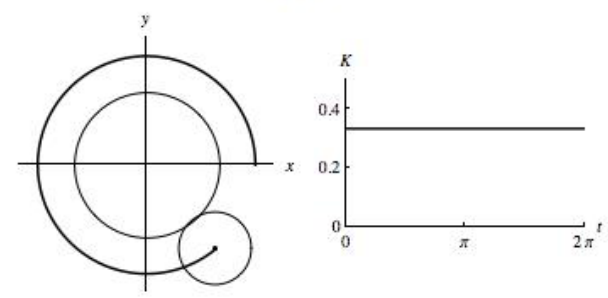

Figure 1: Different epitrochoids for $h=1,2 / 3,1 / 3$ and 0 with the corresponding curvature function $K(t)$.

Moreover such a curve is as regular as the ellipse and much more regular than an oval made of several circular arcs.

This, implying higher order derivatives, or smooth changes in curvature, affects stresses.

Some additional parameters $c, d$, were introduced to stretch the curve along its axis, for a better adaptation to the vault's shape:

$$
\begin{aligned}
& x=c(R+r) \cos t-h \cos \frac{R+r}{r} t \\
& y=d(R+r) \sin t-h \sin \frac{R+r}{r} t
\end{aligned}
$$




\section{GEOMETRY. The geometric reason for design}

Volume 1

As it is possible to see in Fig:2, the ellipse (blue) doesn't follow the vault shape along the diagonals, and in the middle is very close to a circular arc. The proposed parametric curve $\gamma(u)$ is then an epitrochoid with $R=2, r=1, c=$ $1.5, d=2$ and $h=1 / 3$ :

$$
\gamma(u)=\left(6 \sin u+\frac{1}{3} \sin 3 u, \frac{9}{2} \cos u+\frac{1}{3} \cos 3 u\right)
$$

This particular epitrochoid actually in the middle of the vault has curvature very close to 0 , since it is locally quite similar to a line, whereas in its lateral sides is very close to a circle.

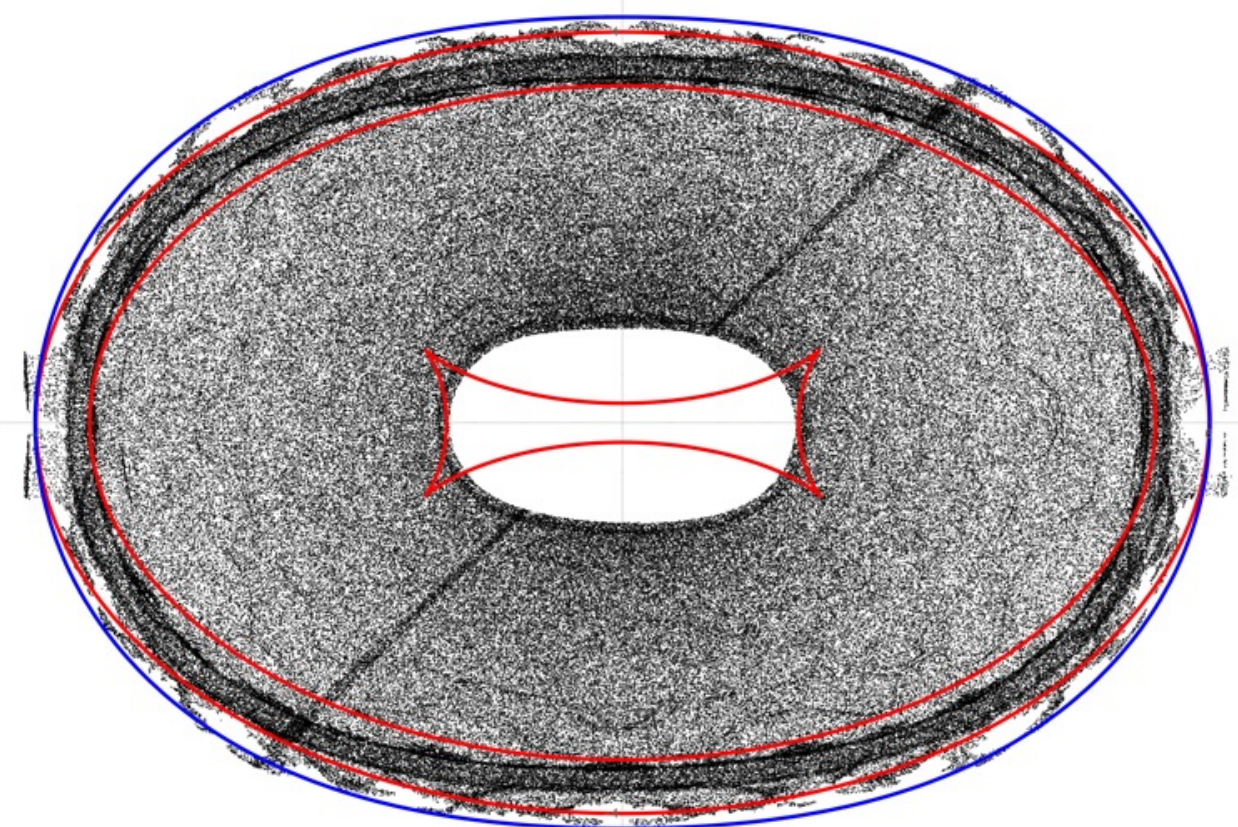

Figure 2: Comparison between a red ellipse and the blue epitrochoid, superimposed to a vertical projection of the point cloud. The black region correspond to the internal decoration and the base curve is found indirectly as a curve at a constant distance from the frame decoration curve

\section{THE SURFACE}

The real problem, solved ingeniously by Borromini, is however to construct a structurally stable surface, which would minimize the stresses and, upon it, a tasselation as regular as possible with an underlined sense of vertical perspective.

Our goal is then to describe a possibly simple mathematical model of the actual vault of S. Carlino which could be tested on a three dimensional rendering of a direct survey.

\section{Simple parametric models}




\section{GEOMETRY. The geometric reason for design}

Volume 1

Here we describe three surface models of the vault and try to measure their validity. Keeping fixed the basis of the vault (the stretched epitrochoid (2.3)) a first simple model of the surface can be contructed on it assuming an ellipsoidal shape (see [6]): in parametric coordinates this can be formulated as a parametric surface $\gamma(u, v)$

$$
\gamma(u, v)=\left(\left(6 \sin u+\frac{1}{3} \sin 3 u\right) \sin v,\left(\frac{9}{2} \cos u+\frac{1}{3} \cos 3 u\right) \sin v, \frac{19}{3} \cos v\right)
$$

where the height of the surface is tentatively chosen to be $19 / 3$ in the chosen units as suggested in fig.6; here the drawn ellipses are all similar to the basis of the vault which implies that the height of the vault is equal to its longer semi-axes.

A second model, with similar features, can be constructed by rotating the basis line around the $y$ axis (along its minor semi-axes).

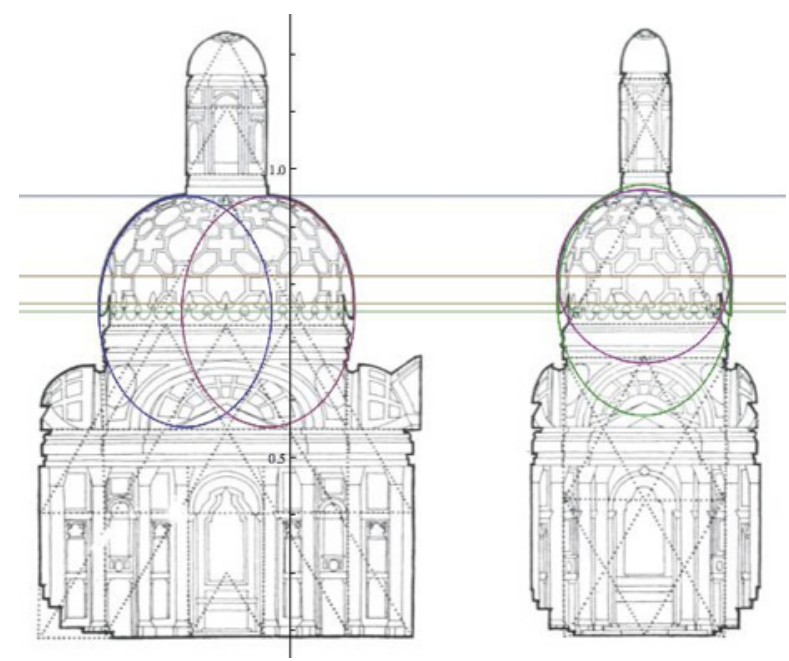

Figure 6: Elliptic and almost circular sections superimposed to a design from a relief by Portoghesi.

Finally, in fig.6 the two sections, basically elliptical (ending at the base of the lantern with horizontal tangency) in one direction and more circular in the other, suggests a different model, more similar to a portion of an elliptical torus (suggestive, thinking of S. Costanza) that is the surface of revolution of an ellipse around a complanar stright line parallel to one of its axis (see fig. 7). 

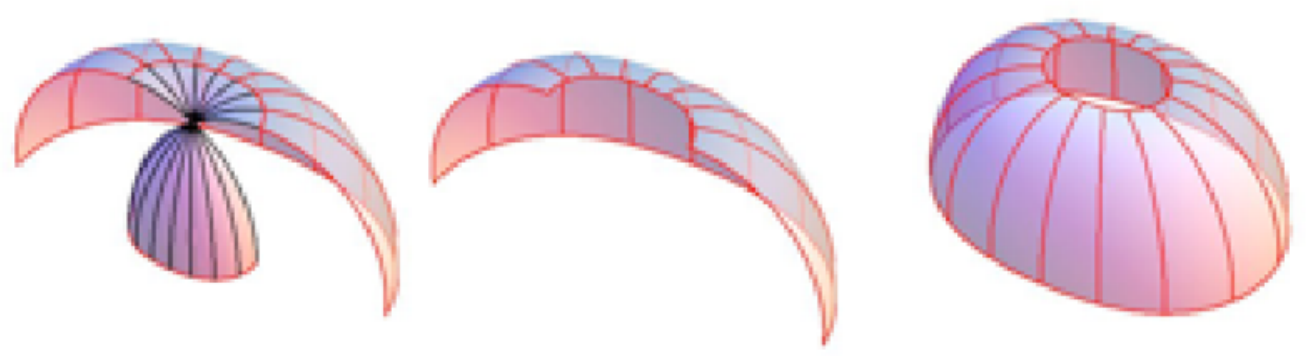

Figure 7: Toric surface defined as an ellipse rotating along the epitrochoid and around a vertical axis which intersects the curve.

In order to fix the corresponding parametric equation of the three models, we have taken a preliminary set of points from a direct relief; with the surface we can then construct also a model of the decorations which we finally want to test with a guided survey and the use of advanced software (like Mathematica and Photomodeler).

We have therefore evaluated the mean distance of a preliminary set of 477 points, taken by a direct survey from the three kind of surfaces with parameters chosen in order to minimize the resulting quantities.

The parametric equations are then:

$$
\begin{gathered}
\gamma_{1}(u, v)=9.31\left(\left(6 \sin u-\frac{1}{3} \sin 3 u\right) \sin v,\left(\frac{3}{2} \pi \cos u-\frac{1}{3} \cos 3 u\right) \sin v, 6.16 \cos v\right) \\
\gamma_{2}(u, v)=9.27\left(\left(6 \sin u-\frac{1}{3} \sin 3 u\right) \sin v,\left(\frac{3}{2} \pi \cos u-\frac{1}{3} \cos 3 u\right),\left(6 \sin u-\frac{1}{3} \sin 3 u\right) \cos v\right) \\
\gamma_{3}(u, v)=6.21\left(\left(6 \sin u-\frac{1}{3} \sin 3 u\right)\left(\frac{1}{2}+\sin v\right),\left(\frac{3}{2} \pi \cos u-\frac{1}{3} \cos 3 u\right)\left(\frac{1}{2}+\sin v\right), 8.55 \cos v\right)
\end{gathered}
$$

all translated by the vector $(5.94,0.3,16.29)$ to localize the model on the given set of points of the point cloud. 


\section{GEOMETRY. The geometric reason for design}

Volume 1

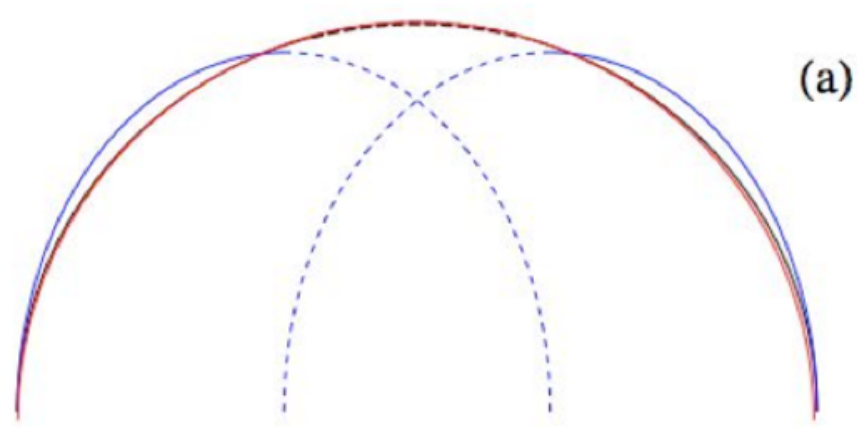

(a)

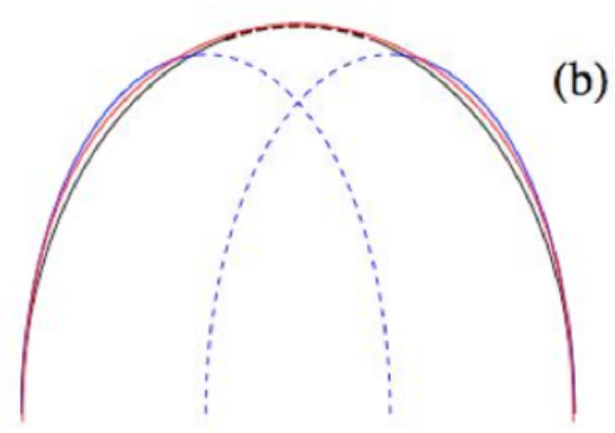

Figure 9: Sections of the three model surfaces $(\gamma 1(u, v)$ black, $\gamma 2(u, v)$ red, $\gamma 3(u, v)$ blue) with the same basis line.

The chosen surfaces are then tested by measuring their mean and maximum distance from the given set of points (see Table 1): the ellipsoidal surface $\gamma 1(\mathrm{u}, \mathrm{v})$ is the closest one whereas the toroidal surface $\gamma 3(\mathrm{u}, \mathrm{v})$ is the worst and the rotated epitrochoid $\gamma 2(\mathrm{u}, \mathrm{v})$ is comparable with $\gamma 1$. Note that the numbers are anyhow very small with respect to the vault size, since they are less than $1 \%$ of its major axis. 


\section{GEOMETRY. The geometric reason for design}

Volume 1

$\begin{array}{lrrrrrr} & \langle\mathrm{d}(\gamma 1)\rangle & \max (\mathrm{d}(\gamma 1)) & \langle\mathrm{d}(\gamma 2)\rangle & \max (\mathrm{d}(\gamma 2)) & \langle\mathrm{d}(\gamma 3)\rangle & \max (\mathrm{d}(\gamma 3)) \\ 1 & & & & & & \\ 2 & 5.68 & 13.89 & 7.51 & 11.43 & 12.32 & 22.98 \\ 3 & 3.15 & 7.71 & 4.95 & 12.25 & 16.51 & 28.40 \\ 4 & 6.87 & 13.90 & 7.37 & 16.90 & 18.81 & 33.60 \\ 5 & 6.07 & 14.67 & 10.41 & 22.52 & 18.87 & 34.48 \\ 6 & 7.59 & 14.25 & 11.69 & 24.04 & 15.04 & 33.91 \\ 7 & 9.01 & 18.77 & 7.43 & 13.89 & 11.96 & 24.67 \\ 8 & 6.30 & 15.53 & 6.84 & 14.62 & 10.66 & 24.43 \\ 9 & 4.16 & 11.24 & 4.93 & 14.14 & 18.81 & 28.87 \\ 10 & 4.93 & 10.53 & 6.19 & 13.46 & 12.45 & 28.63 \\ 11 & 4.31 & 10.49 & 4.87 & 12.65 & 19.94 & 32.97 \\ 12 & 7.95 & 22.19 & 8.69 & 23.31 & 15.29 & 28.98 \\ 13 & 6.85 & 13.83 & 10.98 & 18.24 & 18.55 & 33.59 \\ 14 & 6.16 & 18.27 & 9.55 & 14.56 & 13.61 & 23.85 \\ 15 & 6.14 & 12.81 & 11.12 & 20.72 & 19.87 & 31.76 \\ 16 & 4.90 & 13.44 & 6.15 & 16.19 & 10.64 & 24.87 \\ & 5.12 & 10.01 & 7.91 & 13.63 & 13.46 & 21.23 \\ \text { Total } & 5.95 & 13.85 & 7.91 & 16.41 & 15.43 & 28.58\end{array}$

Table 1: Mean and maximum distance (in $\mathrm{cm}$.) for each of the 16 horizontal sector (in the $u$ variable) between points of the relief and the three different surfaces $\gamma 1(u, v), \gamma 2(u, v), \gamma 3(u, v)$.

(a)

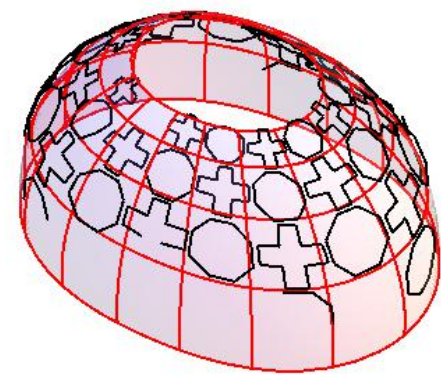

(b)

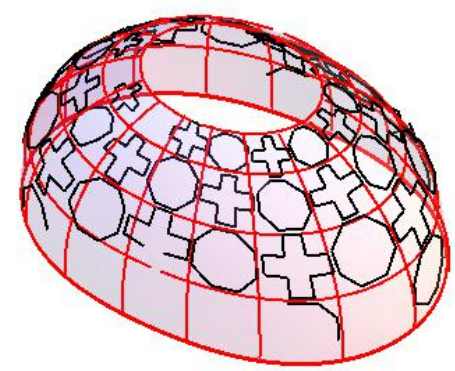

(c)

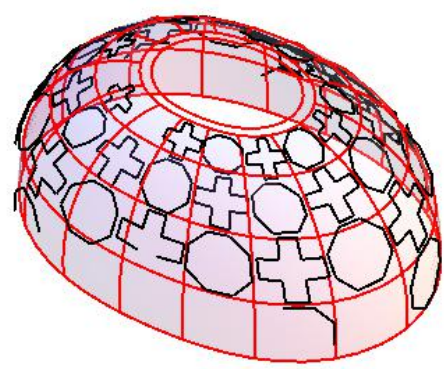

Figure 13: Models of the vault with a decoration sample from the direct survey; (a) $\gamma 1(u, v)$, $b=0.715$; (b) $\gamma 2(u, v), \cos (v)$ in aritmetic progression; (c) $\gamma 3(u, v), v=(0, \pi / 20, \pi / 8, \pi / 4,3 / 8 \pi$, $\pi / 2)$.

\section{Edge-Surfaces from four parametric curves}

Given four intersecting parametric curves, with parameter values normalized in [0,1], it is possible to construct a surface that has the curves as a frame: 


\section{GEOMETRY. The geometric reason for design}

Volume 1

$$
\begin{aligned}
\mathrm{S}(\mathrm{u}, \mathrm{v})=(1-\mathrm{v}) S_{1}(\mathrm{u}, 0)+\mathrm{u} S_{2}(1, \mathrm{v})-\mathrm{v} S_{3}(\mathrm{u}, 1)+(1-\mathrm{u}) S_{4}(0, v) \\
-(1-u)(1-v) S_{1}(0,0)-u(1-v) S_{2}(1,0)-u v S_{3}(1,1) \\
-(1-u) v S_{4}(0,1)
\end{aligned}
$$

This mathematical construction algorithm can be used to get a piece of the surface model using regular parametric curve of sections as discussed in the previous paragraphs.

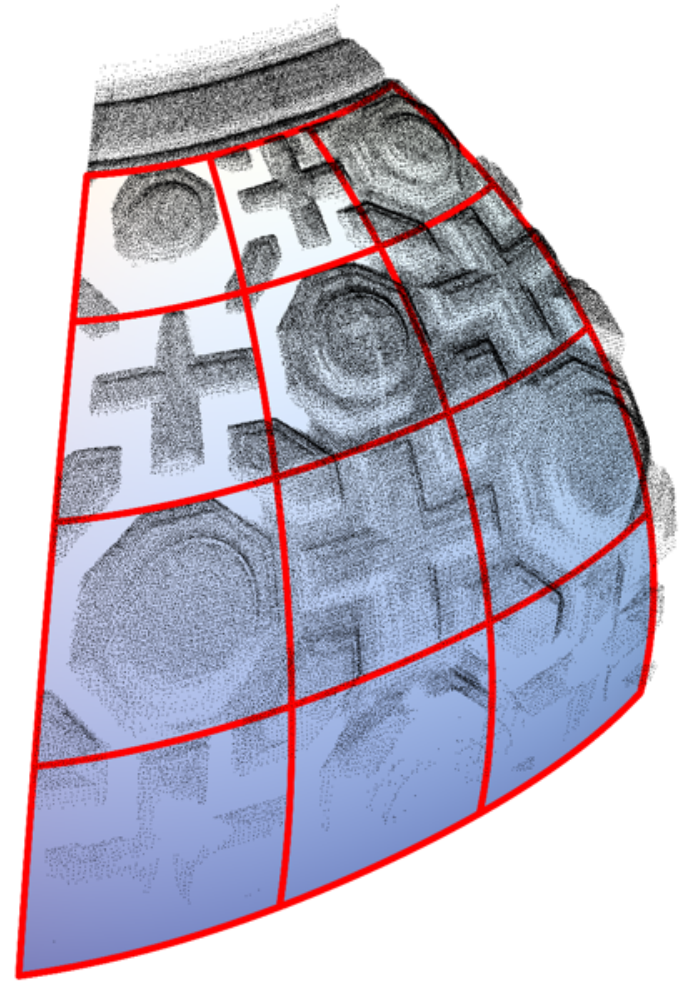

Figure 9: Model of a sector along the large circular arc: the position of the parametric surface based on four given border curves has been optimized.

\section{Three-dimensional ovals}

Starting from the oval of the base curve it is possible to construct a model divided in four sectors corresponding to the four symmetric arcs of the oval. Since also the vertical sections are approximated by circular arcs, the four sectors can be seen as part of a toric surface. 


\section{GEOMETRY. The geometric reason for design}

Volume 1

The centers of the lacunars are also oriented along four different centers (see Figure 16).

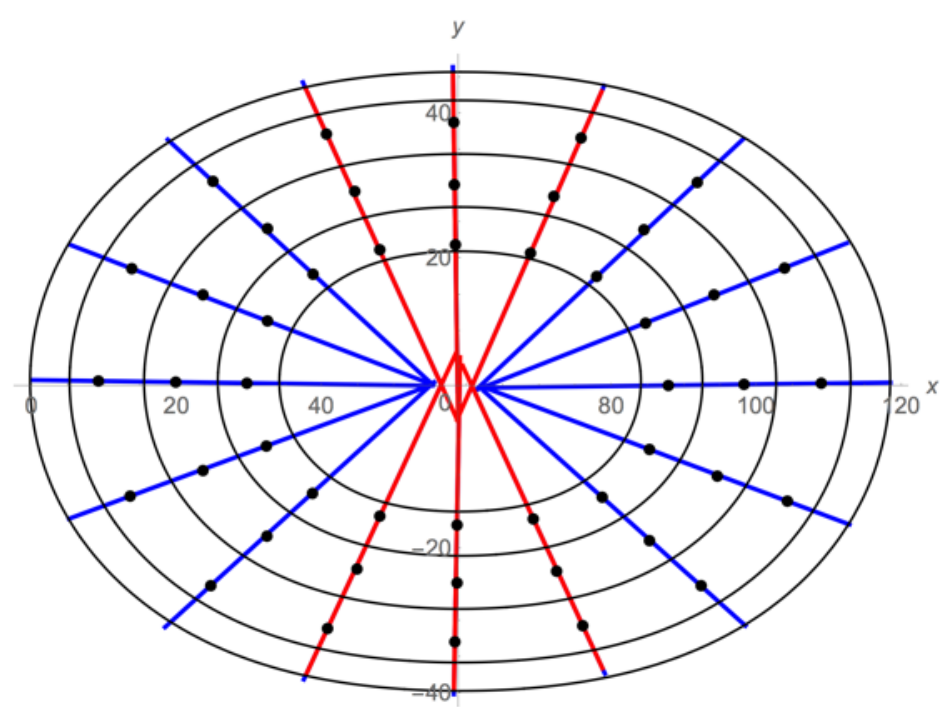

Figure 16: The barycenter of the lacunars (black dots) are alingned towards four different centers.

This suggests the construction using four vertical axis of symmetry passing through such centers, as in Figure 17.

\section{TESSELLATIONS}

\section{The motif with octagons and crosses}
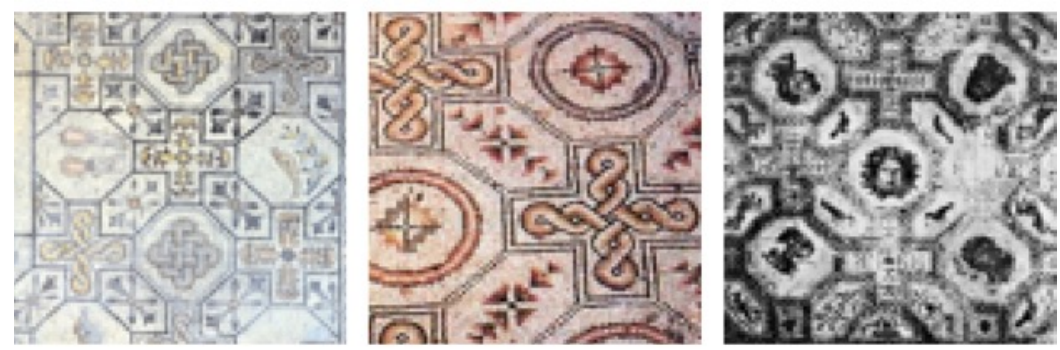

Figure 3: Roman floor mosaics, with the same motif of octagons and crosses, from Aquileia, Piazza Armerina and Pallatina (Spain).

The crosses (symbol of Christianity and of the Order of Padri Trinitari, owner of the church of San Carlino) and octagons tasselation motif of the vault is an ancient roman mosaic floor decoration 


\section{GEOMETRY. The geometric reason for design}

Volume 1

(see Fig.3) which appeared also in the toric vault of S. Costanza: Serlio ([15]) reported this geometrical designs in his book (see Fig. 4).

Some connections between mosaics in S.Costanza, Serlio and Borromini are well established
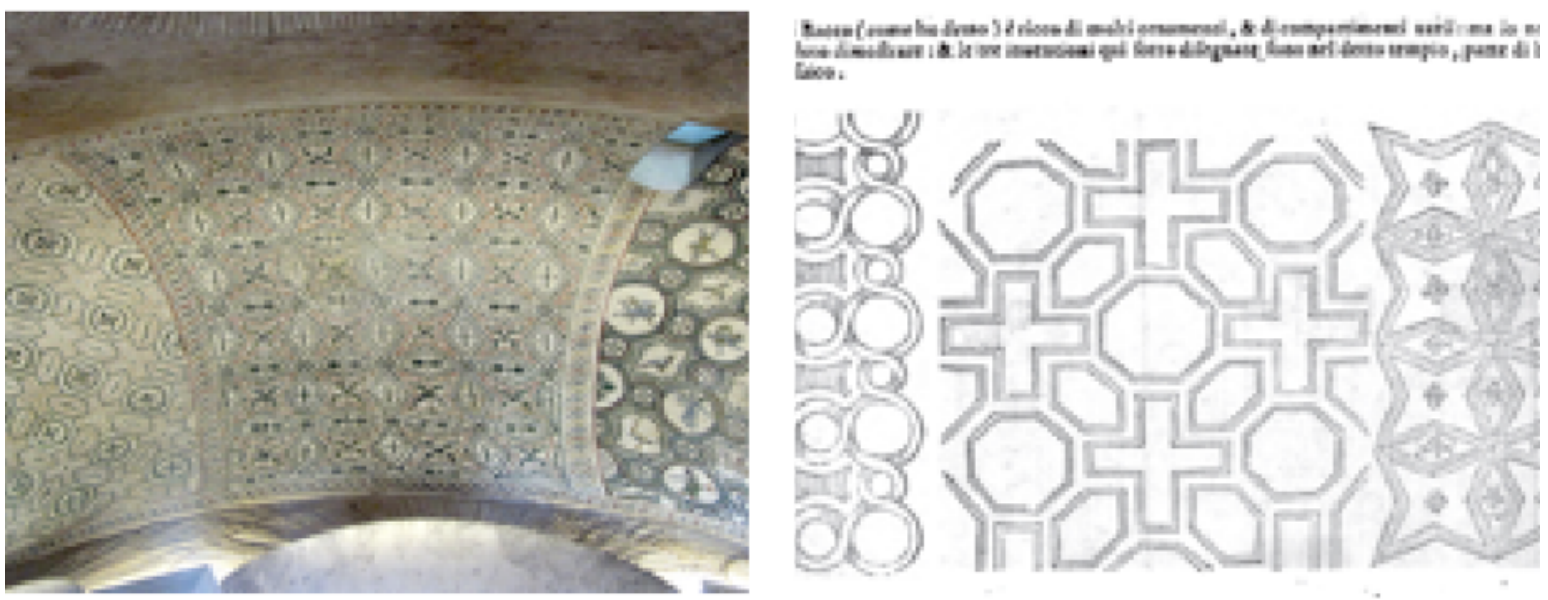

Figure 4: Ornaments in S. Costanza (Roma), then considered the old

Temple of Baccus, as reported in Serlio's Trattato di Architettura, 1540.

(Blunt, 1979) for S. Carlino and (Bruschi, 1978) for a decoration of an architrave in the Oratorio dei Filippini, let's add some curiosity and mathematical considerations.

The particular oval in the project of S. Carlino is related to the Serlio's oval of the fourth kind, based on two circles both passing through the center of the other one: the entire frame of S. Costanza's mosaics is made of a long line of such circles (Fig. 5). In his Libro IV Serlio [15] also suggest esplicitely (with a drawing) a ceiling made by lacunars, again with the same decoration. Moreover, the curvature of the toroidal vault in S. Costanza affects the mosaic design because of the relative size of the rectangular panels which must be distorted and not only curved as in a barrel vault. The effect of such non euclidean iperbolic geometry, even if it had been only a practical solution of a given tessellation (literary) problem, is clearly visible (Fig. 5 and 6) and mathematically is very similar to the problem faced by Borromini: to give the impression, in a non euclidean elliptic geometry, of great regularity as in a planar tessellation. 

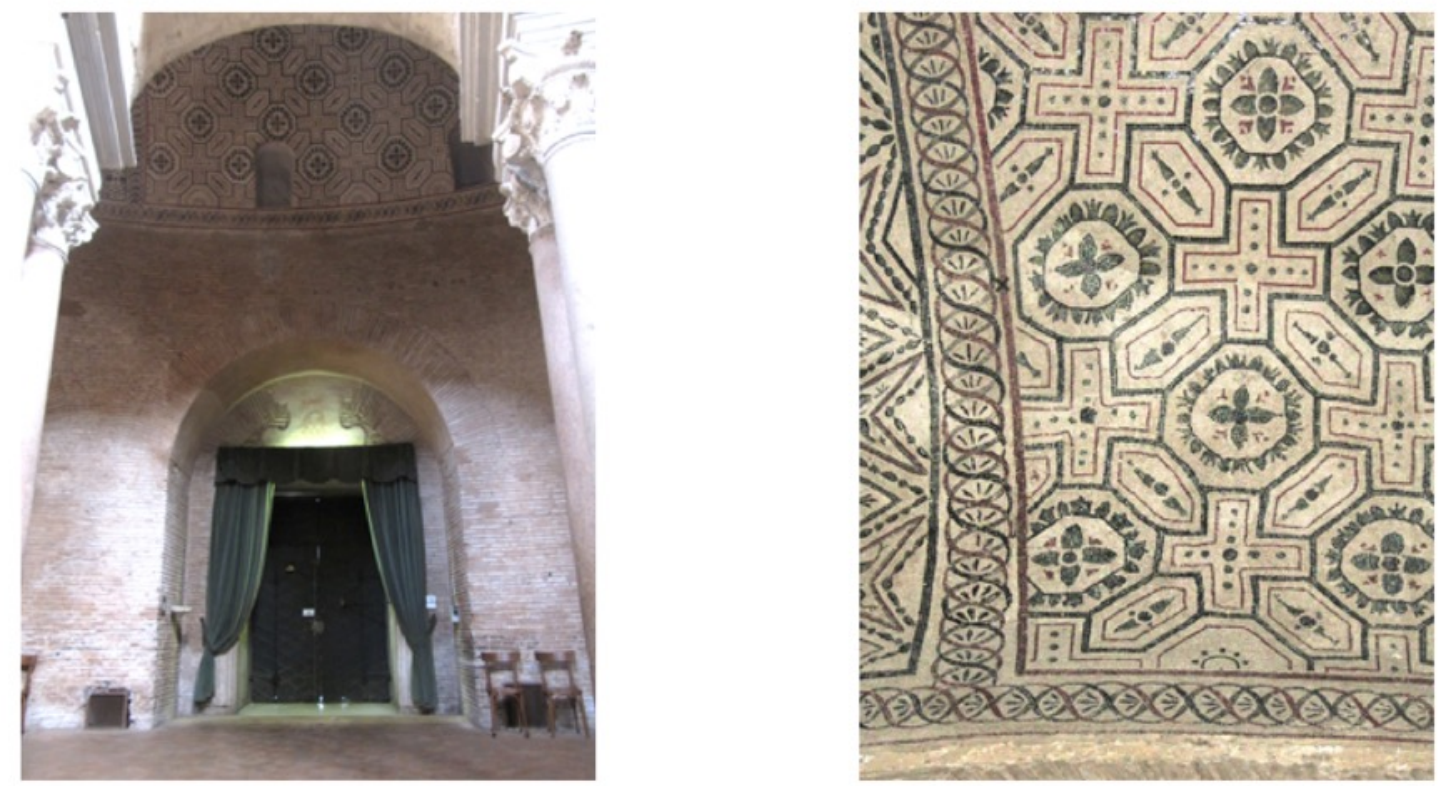

Figure 5: The decoration over the entrance of S. Costanza. A particular of the frame: note the local displacement between the frame and the internal motif.

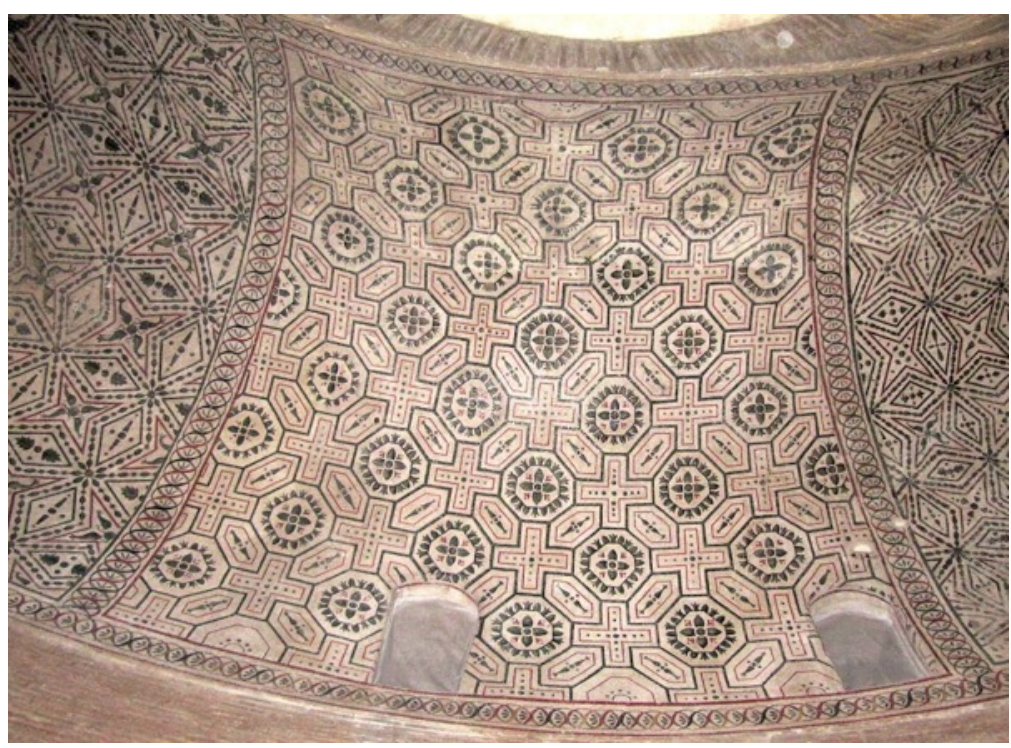




\section{GEOMETRY. The geometric reason for design}

Volume 1

Figure 6: S.Costanza: full panel of the toric vault with the cross-octagons and exhagonal tasselation.

In this respect, for Borromini's task of rendering a planar tasselation in an ellipsoidal-like vault, it could have been more inspirational the practical work of a $4^{\text {th }}$ century mosaic magister rather than a $16^{\text {th }}$ century architect.

The $17^{\text {th }}$ century has been fundamental for the history of both mathematics and architecture, thank to innovative genius like Cartesio and Borromini, but to settle non-euclidean geometry as a formal theory two more centuries were needed: starting from the work of Gerolamo Saccheri [11] in 1733 up to the work of Lobachevsky and Bolyai in 1829-1833. It's nice however to think that one month after the violent death of Borromini (August 3th, 1667) a baby named Gerolamo was born (september $\left.5^{\text {th }}, 1667\right)$.

\section{A parametric model}

The model depends on few parameters defining a given base curve.

The lacunars seems to be bounded by coordinates curves ("parallels" and "meridians") in a very regular pattern: alternating crosses and regular octagons on increasing levels seems to rescale towards the top of the vault. Given the $n^{\text {th }}$ vertical level and the number $N$ of lacunars for any level we can define position and size of a tassel of the surface by the spherical coordinates of its centre $\left(u_{0}, v_{0}\right)$ and the angular "radius" in horizontal $\left(u_{r}\right)$ and vertical $\left(v_{r}\right)$ direction:

$$
\begin{aligned}
& u_{0}=\frac{2 \pi}{N} \\
& v_{0}^{n}=\frac{2 \pi}{N} 2 b^{n}(1+b) \\
& u_{r}^{n}=u_{r}^{0}=\frac{\pi}{N} \\
& v_{r}^{n}=\frac{\pi}{4} b^{n}(1-b)
\end{aligned}
$$

where $b$ is the ratio between vertical radii of two successive tassels, that is

$$
b=\frac{v_{r}^{n+1}}{v_{r}^{n}}
$$

It is possible to check the geometric progression of levels with the help of some graphical tool: in Figure 10 dinamically we could change some parameter, looking for the correct common ratio. 
GEOMETRY. The geometric reason for design

Volume 1

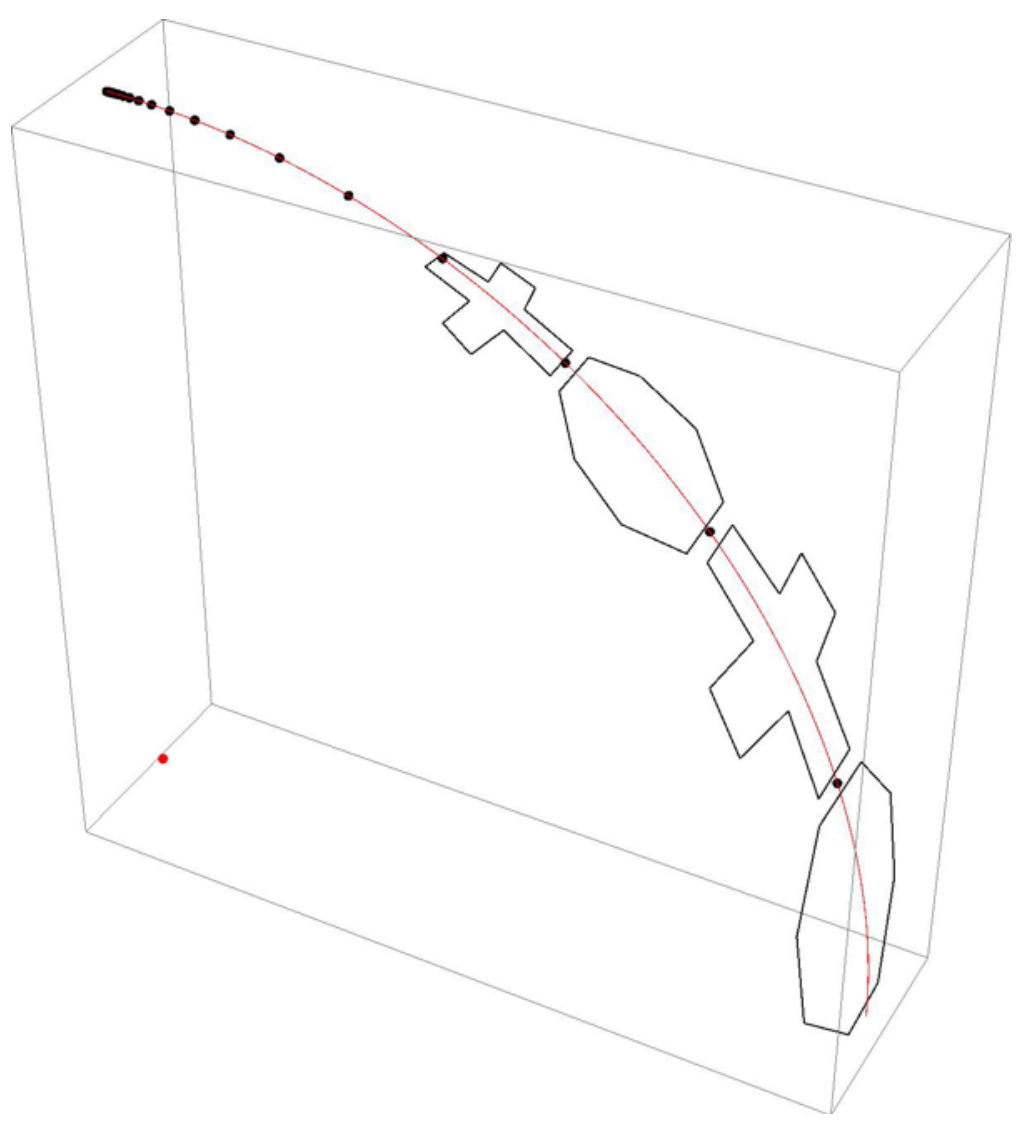

Figure 5: A model of the lacunars based on some reference points at the vertex of octagons and crosses. The black dots indicate the level curves in a geometrical progression.
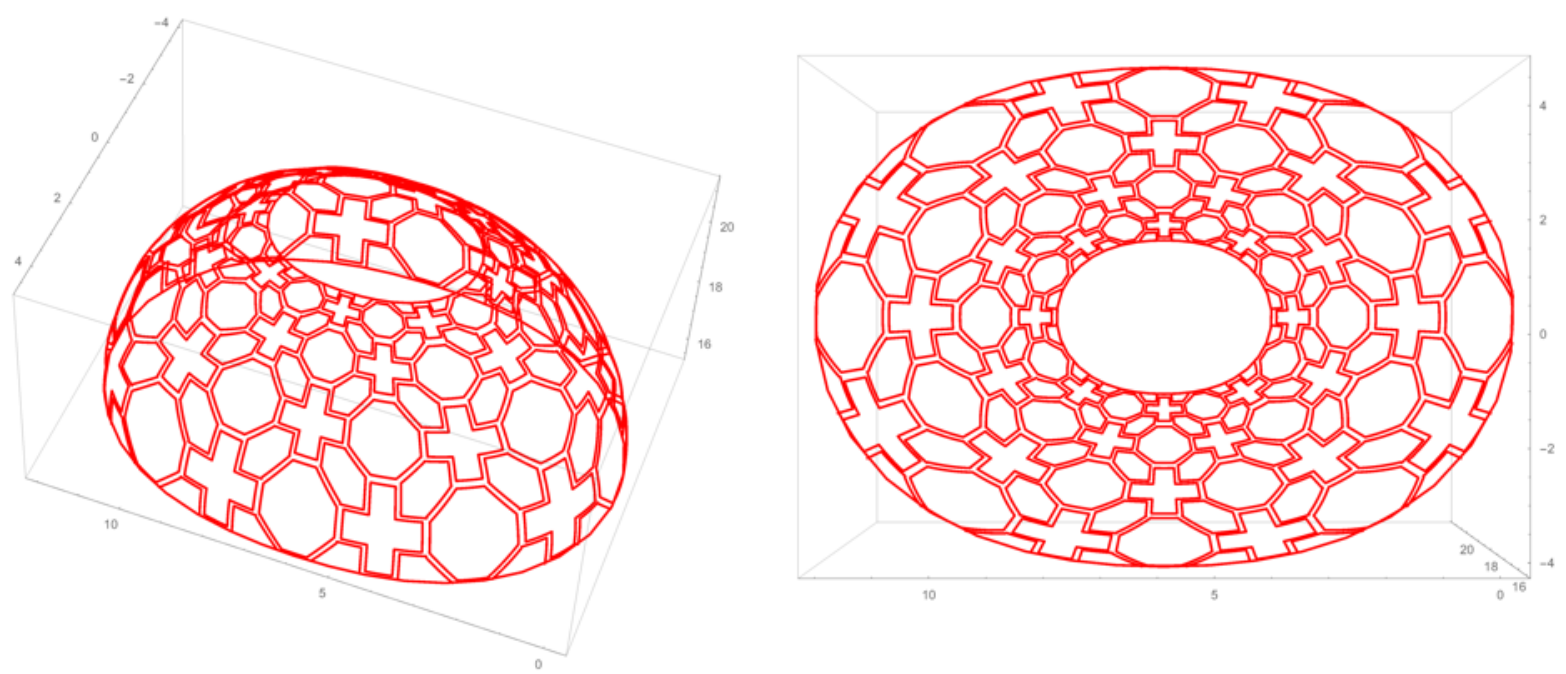


\section{GEOMETRY. The geometric reason for design}

Volume 1

Figure 5: A model of S.Carlino's vault based on an epitrochoidal ellipsoid with $b=0.71$.

In order to fix the value of $b$ and of the vertical size of the first tessel we make (as in Falcolini\&Vallicelli, 2011) two hypothesis:

1) it should be possible to fit an infinite number of successive tassels of constant ratio which ends up exactly at the pole,

2) all tessels have the same size: they should, as much as possible, looks like squares within some accuracy.

These two requirements are at the base of all practical rules to fit domes with regular tessellations which usually tend to the centre of the dome with a perspective sense of infinite height: the general problem is more relevant when the surface is not regular or lack some simmetry.

The first hypothesis implies that the sum of the vertical size of the infinite tassels in angular coordinates would be exactly $\pi / 2$, which gives the condition:

that is

$$
\frac{\pi}{2}=\sum_{k=0}^{\infty} 2 v_{r}^{k}=\sum_{k=0}^{\infty} 2 v_{r}^{0} b^{k}=2 v_{r}^{0} \sum_{k=0}^{\infty} b^{k}=2 v_{r}^{0} \frac{1}{1-b}
$$

$$
v_{r}^{0}=\frac{\pi}{4}(1-b)
$$

The second condition, tassels of similar size on both vertical and horizontal direction, in a spherical approximation of the surface can be fixed by the condition (which depends on the vertical position of the tessel)

$$
v_{r}^{n}=\frac{\pi}{N} \sin v_{0}^{n}
$$

or more explicitly

$$
\sin \left(\frac{4 \pi}{N} b^{n}(1+b)\right)=\frac{N}{4} b^{n}(1-b)
$$

In our case $N=16$ and the relation leads to

$$
\sin \left(\frac{\pi}{4} b^{n}(1+b)\right)=4 b^{n}(1-b)
$$

that for $\mathrm{n}=1$ has an approximate numerical solution of $\mathrm{b}=0.712913$.

For large $n$ the approximate condition $\sin (\mathrm{x}) \approx \mathrm{x}$ holds and for $N=16$ one gets 


\section{GEOMETRY. The geometric reason for design}

Volume 1

$$
b=\frac{N^{2}-16 \pi}{N^{2}+16 \pi}=\frac{16-\pi}{16+\pi}=0.671752 \ldots
$$

a value which guaratees a regular tasselation for any number of (smaller and smaller) levels.

Since the surface is far from spherical some more detailed analysis is needed .

Here we have shown reasonable values of $b$ for the models under scrutiny, looking for a graphical control of the prescribed rules for the first levels of the tasselation and keeping fixed the general properties of regularity.

We have written program codes, using Mathematica software (in Appendix), to automatically compute a generic regular tasselation of a given parametric surface evaluating the accuracy of its representation.

An example of a complete model is then superimposed to the points cloud.

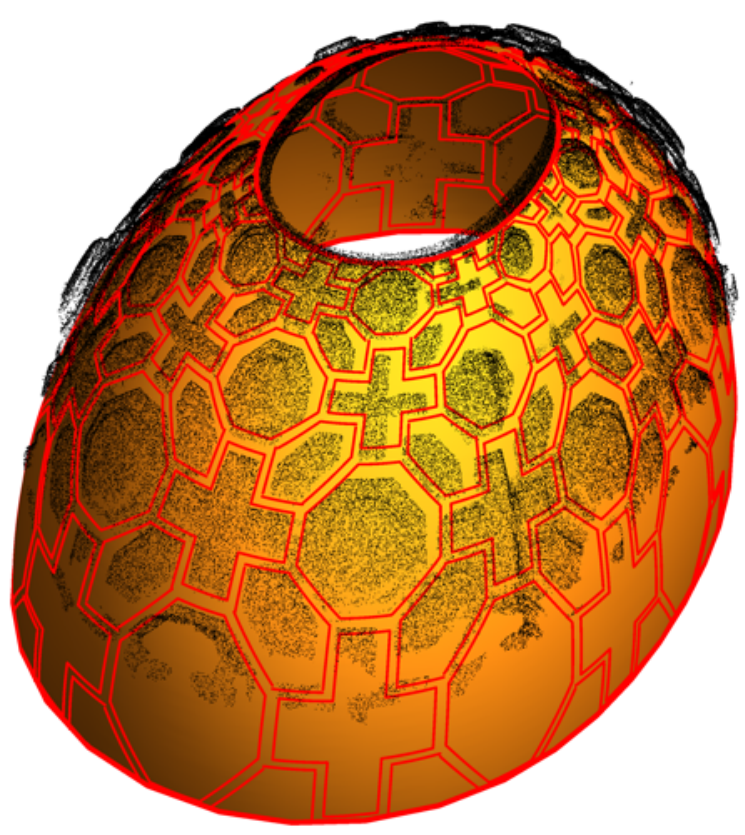

Figure 5 A tessellation model $(b=0.71)$ superimposed to a chosen surface and to the points cloud. 


\section{GEOMETRY. The geometric reason for design}

Volume 1

The parametric nature of the automatic algorithm presented here (see the Appendix) to produce different models allows us to apply the same structure of the surface or the decorations but with relevant changes in some of the parameters: on Figure 6a for example is shown the same decoration and the surface is still an ellipsoid built over an epitrochoid but the distance $h$ of the fixed point from the center of the rolling circle is 2 instead of $1 / 3$; in Figure $6 b$ the surface is still an ellisoid on the same epitrochoid of S.Carlino but the number of lacunars per level is 23 instead of 16 on 10 levels instead of 4 .
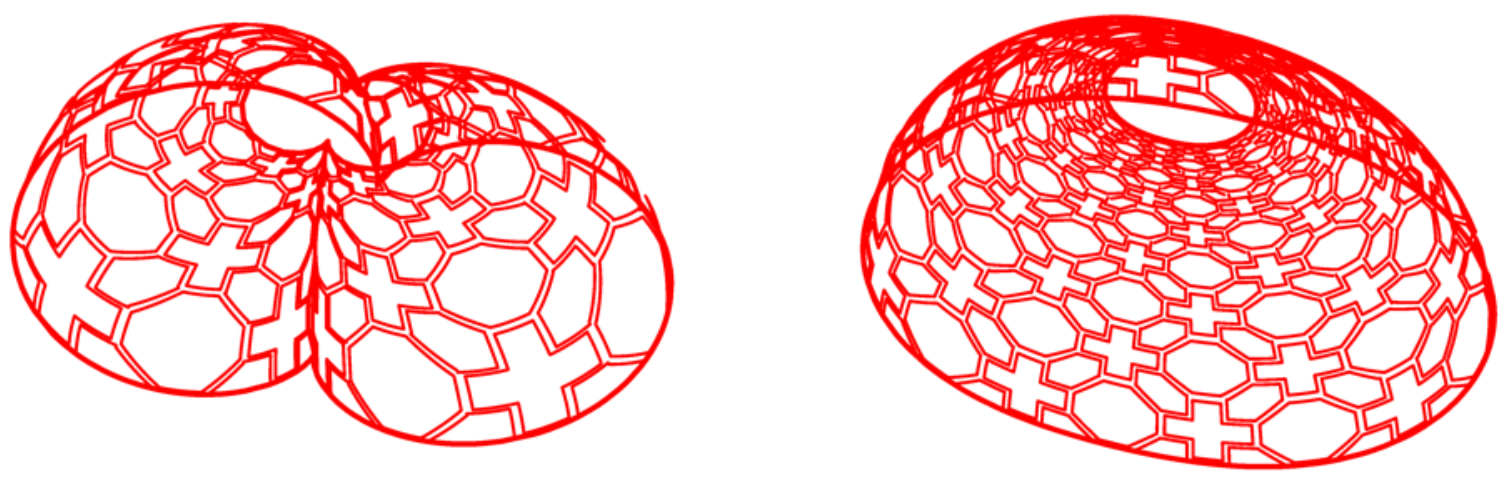

Figure 6: Same tessellation on a different surface with $h=2$ (left) and on the same surface with $n=8$ and $b=.82$ (right).

If we keep fixed the surface and increase the number $\mathrm{n}$ of lacunar levels we see that the uniform shape of the tessels is preserved; in Figure 7 the only difference on the two images is the star-like connection (left) of the 12 vertex points of the cross tessel. Note the "familiar" shape of the curves formed by this simple change in the algorithm. 


\section{GEOMETRY. The geometric reason for design}

Volume 1
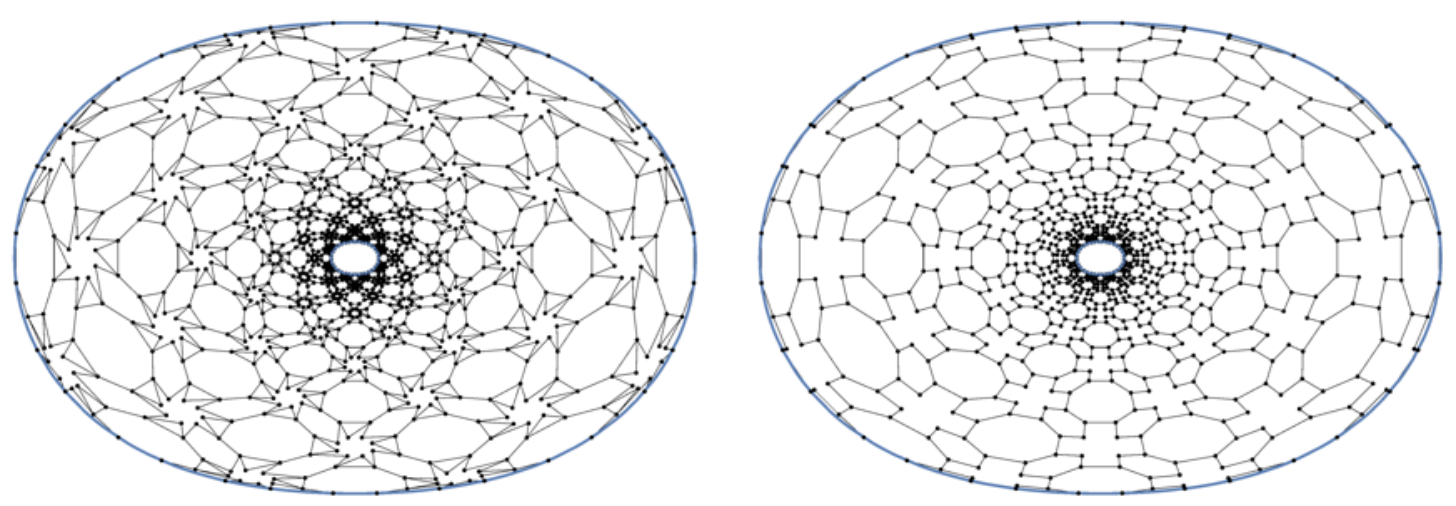

Figure 7: Different tessellations over the same surface with more levels: the only difference on the left is the star-like connection of the 12 vertex points of the cross tessel.

\section{REFERENCES}

AA.VV. (2007). La "Fabrica" di San Carlo alle Quattro Fontane: gli anni del restauro. Volume speciale del "Bollettino d'arte".

Blunt A. (1979). Borromini, Harvard University Press, England.

Bruschi, A. (1978). Borromini, manierismo spaziale oltre il barocco, Dedalo libri.

Canciani, M., Falcolini, C., Spadafora, G., \& Saccone, M. (2013). From point clouds to architectural models: algorithms for shape reconstruction. ISPRS Archives, XL-5(W1), 27-34.

Canciani, M., Falcolini, C., \& Spadafora, G. (2013). From complexity of architecture to geometrical rule. The case study of the dome of San Carlino alle Quattro Fontane in Rome. In Proceedings of X Forum internazionale di studi Le vie dei Mercanti, 16.

Falcolini, C., \& Vallicelli, M. (2011). Modelling the vault of San Carlo alle Quattro Fontane. Aplimat Journal of Applied Mathematics, 4(4), 143-150.

Huerta, S. (2007). Oval Domes: History, Geometry and Mechanics, Nexus Network Journal - vol. 9, N. 2.

Portoghesi, P. (1967). Borromini. Architettura come linguaggio. Milano: Electa.

Saccheri, G. (1733). Euclide ab omni naevo vindicatus, Milano.

Sartor, A. (2000). Il rilievo della fabbrica di San Carlo Alle Quattro Fontane. In Borromini e l'universo barocco. Roma, Electa. 


\section{GEOMETRY. The geometric reason for design}

Volume 1

Serlio, S. (1566) Trattato di Architettura, Venezia.

\section{ADDITIONAL READING}

Abate, M., \& Tovena, F. (2006). Curve e superfici. Springer.

Ahn, S.J. (2008). Geometric Fitting of Parametric Curves and Surfaces, Journal of Information Processing Systems, Vol.4, No.4

Bellini, F. (2004). Le cupole di Borromini. La «scienza» costruttiva in età barocca, Electa.

Degni, P. (2000). San Carlo alle Quattro Fontane. Annotazioni sui restauri eseguiti e in corso, in Francesco Borromini, Milano, Electa, 372-380.

Do Carmo, M. (1976). Differential Geometry of Curves and Surfaces. Prentice-Hall.

Elber, G., \& Grandine, T. (2010) Hausdorff and Minimal Distances between Parametric Freeforms in $R^{2}$ and $R^{3}$, Vis Comput 26: 1007-1016

Galizia M., \& Santagati C. (2012). Architecture and/is Geometry: from the architectural shape to the geometrical construction, DISEGNARECON, 5 (9), 135-144.

Gray, A., Abbena, E., \& Salamon S. (2006). Modern Differential Geometry of Curves and Surfaces with Mathematica

Kahn-Rossi, M., \& Franciolli, M. (1999). Il giovane Borromini. Dagli esordi a San Carlo alle Quattro Fontane, Catalogo della mostra (Lugano, 5 sett. - 14 nov.), Skira, Milano.

Kim, Y.J., Oh, Y.T., Yoon, S.H., Kim, M.S. \& Elber, G. (2008) Precise Hausdorff distance computation for planar freeform curves using biarcs and depth buffer. In: Chen, F., Jüttler, B. (eds.) Advances in Geometric Modeling and Processing

Marconi, P. (1967). La Roma del Borromini, Capitolium, 42 (12).

Memoli, F., \& Sapiro, J. (2001). Fast computation of weighted distance functions and geodesics on implicit hypersurfaces. Journal of Computational Physics, 173(2), 730-764.

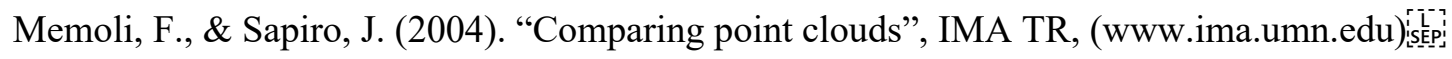

Norberg- Schulz, C. (1999). Architettura barocca, Electa, Milano.

Portoghesi, P. (2001). Storia di San Carlino alle Quattro Fontane, Newton \& Compton.

Pottmann, H., \& Wallner, J. (2001). Computational Line Geometry. Springer. 


\section{GEOMETRY. The geometric reason for design}

Volume 1

Pottmann, H., Asperl, A., Hofer, M., \& Kilian, A. (2007). Architectural Geometry, Bentley Institute Press.

Sartor, A., Gimenez Molina, M., \& Paduano, I. (2010). Disegno, Architettura, Rilievo. In Proceedings Congreso Internacional EGA. Valencia.

Schlimme, H. (2009). Santa Margherita at Montefiascone and Carlo Fontana's knowledge on Dome Construction, Proceedings: International Congress on Construction History, Cottbus.

Steinberg, L. (1977). Borromini's San Carlo alle Quattro Fontane. A study in multiple form and architectural symbolism, New York. 


\section{GEOMETRY. The geometric reason for design}

Volume 1

\section{ACKNOWLEDGEMENTS}

I wish to thank Marco Canciani for many useful discussions. A special thank to Padre Vincenzo Basterra, Rettore of San Carlo alle Quattro Fontane, for his kind ospitality during the surveys and to the Order of Padri Trinitari.

\section{KEY TERMS AND DEFINITIONS}

Algorithm: a self-contained step-by-step set of operations to be performed.

Epicycloid: a plane curve produced by tracing the path of a chosen point of a circle which rolls without slipping around a fixed circle.

Epitrochoid: a plane curve produced by tracing the path of a point at a given distance from the center of a circle which rolls without slipping around a fixed circle.

Mathematical model: a description of a system_using mathematical concepts and language.

Oval: a symmetrical differentiable curve constructed from two pairs of arcs, with two different radii.

Parametric curve: an expression of the coordinates of the generic point of a curve as a function of one variable, called a parameter.

Parametric surface: an expression of the coordinates of the generic point of a surface as a function of two variables.

Point cloud: a set of three-dimensional data points in some coordinate system.

Tessellation: is the tiling of a surface using one or more geometric shapes, called tiles, with no overlaps and no gaps.

Torus: a surface of revolution generated by revolving a circle in three-dimensional space about an axis coplanar with the circle. 


\section{GEOMETRY. The geometric reason for design}

Volume 1

\section{APPENDIX}

Wolfram Mathematica graphics commands for a model of San Carlino tessellation over a generic parametric surface sup $=\mathrm{S}(\mathrm{u}, \mathrm{v})$ depending on the value of the ratio $\mathrm{b}$, the number of levels $\mathrm{M}$ and the number $\mathrm{N}$ of lacunars on a given level.

$(\mathrm{u} 0, \mathrm{v} 0)$ is the center of a tessel and ur,vr are the horizontal and vertical radius (in angular coordinates) of the tassel.

$\operatorname{octagon}[\sup ]\left[\left\{\mathrm{u} 0 \_, \mathrm{v} 0_{-}\right\}\right]\left[\mathrm{ur}_{-}, \mathrm{vr}\right]:=\operatorname{Show}[\{$

ParametricPlot3D[ $\{\sup / . \mathrm{v} \rightarrow \mathrm{v} 0+\mathrm{vr}, \sup / . \mathrm{v} \rightarrow \mathrm{v} 0-\mathrm{vr}\},\{\mathrm{u}, \mathrm{u} 0-\mathrm{ur} / 3, \mathrm{u} 0+\mathrm{ur} / 3\}]$,

ParametricPlot3D[ $\{\sup / . \mathrm{u} \rightarrow \mathrm{u} 0+\mathrm{ur}, \sup / . \mathrm{u} \rightarrow \mathrm{u} 0-\mathrm{ur}\},\{\mathrm{v}, \mathrm{v} 0-\mathrm{vr} / 3, \mathrm{v} 0+\mathrm{vr} / 3\}]$,

ParametricPlot3D[

$\{\sup / . \mathrm{v} \rightarrow \mathrm{vr} / \mathrm{ur}(\mathrm{u}-\mathrm{u} 0)+\mathrm{v} 0+4 / 3 \mathrm{vr}, \sup / . \mathrm{v} \rightarrow-\mathrm{vr} / \mathrm{ur}(\mathrm{u}-\mathrm{u} 0)+\mathrm{v} 0-4 / 3 \mathrm{vr}\},\{\mathrm{u}, \mathrm{u} 0-\mathrm{ur}, \mathrm{u} 0-\mathrm{ur} / 3\}]$, ParametricPlot3D[

$\{\sup / . \mathrm{v} \rightarrow \mathrm{vr} / \mathrm{ur}(\mathrm{u}-\mathrm{u} 0)+\mathrm{v} 0-4 / 3 \mathrm{vr}, \sup / \mathrm{v} \rightarrow-\mathrm{vr} / \mathrm{ur}(\mathrm{u}-\mathrm{u} 0)+\mathrm{v} 0+4 / 3 \mathrm{vr}\},\{\mathrm{u}, \mathrm{u} 0+\mathrm{ur} / 3, \mathrm{u} 0+\mathrm{ur}\}]$ \}]

$\operatorname{cross}[\sup ]\left[\left\{\mathrm{u} 0, \mathrm{v} 0_{-}\right\}\right][\mathrm{ur}, \mathrm{vr}]:=\operatorname{Show}[\{$

ParametricPlot3D[\{sup $/ . \mathrm{v} \rightarrow \mathrm{v} 0+\mathrm{vr}, \sup / . \mathrm{v} \rightarrow \mathrm{v} 0-\mathrm{vr}\},\{\mathrm{u}, \mathrm{u} 0-\mathrm{ur} / 3, \mathrm{u} 0+\mathrm{ur} / 3\}]$,

ParametricPlot3D[ $\{\sup / . \mathrm{u} \rightarrow \mathrm{u} 0+\mathrm{ur}, \sup / . \mathrm{u} \rightarrow \mathrm{u} 0-\mathrm{ur}\},\{\mathrm{v}, \mathrm{v} 0-\mathrm{vr} / 3, \mathrm{v} 0+\mathrm{vr} / 3\}]$,

ParametricPlot3D[ $\{\sup / . \mathrm{v} \rightarrow \mathrm{v} 0-\mathrm{vr} / 3, \sup / \mathrm{v} \rightarrow \mathrm{v} 0+\mathrm{vr} / 3\},\{\mathrm{u}, \mathrm{u} 0-\mathrm{ur}, \mathrm{u} 0-\mathrm{ur} / 3\}]$,

ParametricPlot3D[ $\{\sup / . \mathrm{u} \rightarrow \mathrm{u} 0-\mathrm{ur} / 3, \sup / . \mathrm{u} \rightarrow \mathrm{u} 0+\mathrm{ur} / 3\},\{\mathrm{v}, \mathrm{v} 0-\mathrm{vr}, \mathrm{v} 0-\mathrm{vr} / 3\}]$,

ParametricPlot3D[ $\{\sup / . \mathrm{v} \rightarrow \mathrm{v} 0-\mathrm{vr} / 3, \sup / \mathrm{v} \rightarrow \mathrm{v} 0+\mathrm{vr} / 3\},\{\mathrm{u}, \mathrm{u} 0+\mathrm{ur} / 3, \mathrm{u} 0+\mathrm{ur}\}]$,

ParametricPlot3D[ $\{\sup / . \mathrm{u} \rightarrow \mathrm{u} 0-\mathrm{ur} / 3, \sup / \mathrm{u} \rightarrow \mathrm{u} 0+\mathrm{ur} / 3\},\{\mathrm{v}, \mathrm{v} 0+\mathrm{vr} / 3, \mathrm{v} 0+\mathrm{vr}\}]$

\}]

Show $[\{$

Table[

$\operatorname{cross}[\sup ]\left[\left\{\mathrm{h} \mathrm{Pi} / 8, \mathrm{Pi} / 4 \mathrm{~b}^{\wedge} \mathrm{n}(1+\mathrm{b})\right\}\right]\left[\mathrm{Pi} / 16, \mathrm{Pi} / 4 \mathrm{~b}^{\wedge} \mathrm{n}(1-\mathrm{b})\right]$,

$\{\mathrm{n}, 0, \mathrm{M}, 2\},\{\mathrm{h}, 1, \mathrm{~N}, 2\}]$,

Table[

octagon[sup] $\left[\left\{(\mathrm{h}+1) \mathrm{Pi} / 8, \mathrm{Pi} / 4 \mathrm{~b}^{\wedge} \mathrm{n}(1+\mathrm{b})\right\}\right]\left[\mathrm{Pi} / 16, \mathrm{Pi} / 4 \mathrm{~b}^{\wedge} \mathrm{n}(1-\mathrm{b})\right]$,

$\{\mathrm{n}, 1, \mathrm{M}, 2\},\{\mathrm{h}, 2, \mathrm{~N}, 2\}]$,

Table[

octagon $[\sup ]\left[\left\{(\mathrm{h}+1) \mathrm{Pi} / 8, \mathrm{Pi} / 4 \mathrm{~b}^{\wedge} \mathrm{n}(1+\mathrm{b})\right\}\right]\left[\mathrm{Pi} / 16, \mathrm{Pi} / 4 \mathrm{~b}^{\wedge} \mathrm{n}(1-\mathrm{b})\right]$,

$\{\mathrm{n}, 0, \mathrm{M}, 2\},\{\mathrm{h}, 1, \mathrm{~N}, 2\}]$,

Table[

cross $[\sup ]\left[\left\{\mathrm{h} \mathrm{Pi} / 8, \mathrm{Pi} / 4 \mathrm{~b}^{\wedge} \mathrm{n}(1+\mathrm{b})\right\}\right]\left[\mathrm{Pi} / 16, \mathrm{Pi} / 4 \mathrm{~b}^{\wedge} \mathrm{n}(1-\mathrm{b})\right]$,

$\{\mathrm{n}, 1, \mathrm{M}, 2\},\{\mathrm{h}, 2, \mathrm{~N}, 2\}]$,

ParametricPlot3D[sup $/ . \mathrm{v} \rightarrow \mathrm{Pi} / 2,\{\mathrm{u}, 0,2 \mathrm{Pi}\}]$,

ParametricPlot3D[sup $\left./ . \mathrm{v} \rightarrow \mathrm{Pi} / 2 \mathrm{~b}^{\wedge}(\mathrm{M}+1),\{\mathrm{u}, 0,2 \mathrm{Pi}\}\right]$

\}$]$ 